\title{
Early Entrance Coproduction Plant
}

Phase I

Preliminary Concept Report

\author{
May 17, 2001 \\ DOE Cooperative Agreement \\ No. DE-FC26-99FT40658
}

Book 1

Tasks 1-3 


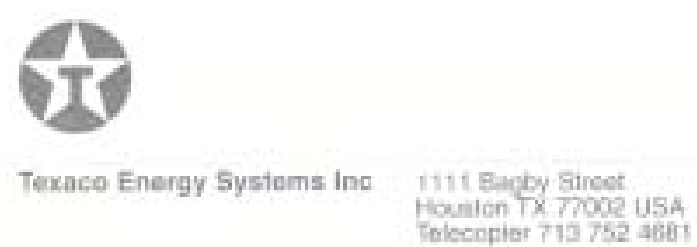

May 17,2001

NETL AAD DOCUMENT CONTROL BLDG. 921

U. S. Department of Energy

National Energy Technology Laboratory

P. O. Box 10940

Pittsburgh, Pennsylvania 15236-0940

Attention: Reports Coordination

Subject: DOE Cooperative Agreement No. DE-FC26-99FT40658

Early Entrance Coproduction Plant

Phase I - Concept Report

Letter No. Tx:DOE:020T

Please refer to the subject Cooperative Agreement. As required by Section IV. attachment B, "Federal Assistance Reporting Checklist" attached are two copies of the Phase I Concept Report Sections: Title Page through List of Acronyms which replace the same sections of the concept report. This report is the final report with the placement of these sections into the report submitted on December 28, 2000.

Also enciosed with each copy of the replacement sections, is a CD containing an electronic version of the complete final document in Adobe Acrobat format (pdf).

Should you have any questions, please contact me at 713-752-4754 or by fax at $713-752-4681$.

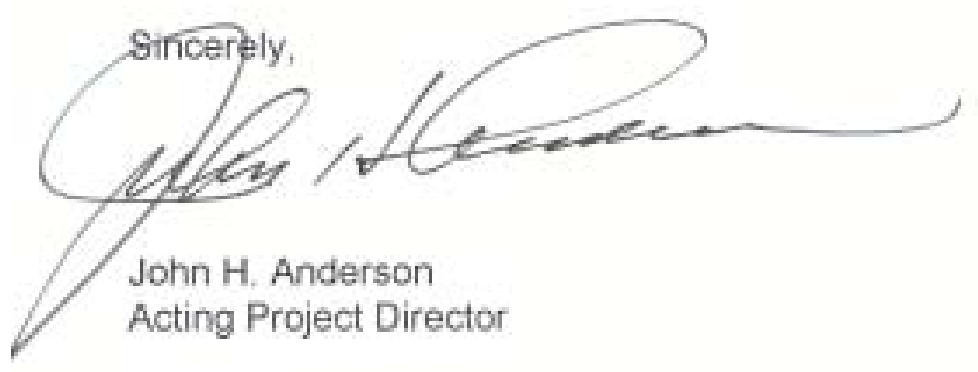

JHA:sms

enciosure

cc: Robert Kornosky - Pittsburgh, PA 


\section{Early Entrance Coproduction Plant Phase I Concept Report}

Reporting Period: October 1, 1999 - December 31, 2000

Principal Authors: John S. Abughazaleh (KBR)

Mushtaq Ahmed (Praxair)

Ashok Anand (GE)

John H. Anderson (TESI)

Charles Benham (Rentech)

Fred D. Brent (Texaco)

Thomas E. Chance (GE)

William K. Davis (Texaco)

Raymond F. Drnevich (Praxair)

Larry Hall (KBR)

Ming $\mathrm{He}$ (Texaco)

Stephen A. Lang (KBR)

David Mintner (KBR)

Wendy Moore (KBR)

Jimmy O. Ong (Texaco)

George Potoczniak (KBR)

Adela G. Sanchez (Texaco)

Charles H. Schrader (TESI)

Lalit S. Shah (Texaco)

Kalapi D. Sheth (Texaco)

Phil J. Shires (KBR)

Rae Song (Texaco)

Date Issued: $\quad$ May 17, 2001

\section{DOE Cooperative Agreement No. DE-FC26-99FT40658}

Texaco Energy Systems Inc.

1111 Bagby Street

Houston, TX 77007 


\section{DISCLAIMER}

This report was prepared as an account of work sponsored by an agency of the United States Government. Neither the United States Government or any agency thereof, nor any of their employees, makes any warranty, express or implied, or assumes any legal liability or responsibility for the accuracy, completeness, or usefulness of any information, apparatus, product, or process disclosed, or represent that its use would not infringe privately owned rights. Reference herein to any specific commercial product, process or service by trade name, trademark, manufacturer, or otherwise does not necessarily constitute or imply its endorsement, recommendation, or favoring by the United States Government or any agency thereof. The views and opinions of authors expressed herein do not necessarily state or reflect those of the United States Government or any agency thereof. 


\section{ABSTRACT}

The overall objective of this project is the three-phase development of an Early Entrance Coproduction Plant (EECP) that produces at least one product from at least two of the following three categories:

- Electric power (or heat)

- Fuels

- Chemicals

The objective is to have these products produced by technologies capable of using synthesis gas derived from coal and/or some other carbonaceous feedstock, such as petroleum coke.

The objective of Phase I was to determine the feasibility and define the concept for the EECP located at a specific site and to develop a Research, Development, and Testing (RD\&T) Plan for implementation in Phase II. This objective has now been accomplished. A specific site, Motiva Refinery in Port Arthur, Texas, has been selected as the location best suited for the EECP. The accomplishments of Phase I are discussed in detail in this Phase I Concept Report. A RD\&T Plan and a preliminary project financing plan have been developed and are submitted separately from this report.

The objective of Phase II is to implement the research, development, and testing work as outlined in the RD\&T Plan to enhance the development and commercial acceptance of coproduction technology that produces high-value products, particularly those that are critical to our domestic fuel and power requirements. The project will resolve critical knowledge and technology gaps on the integration of gasification and downstream processing to coproduce some combination of power, fuels, and chemicals from coal and/or other feedstocks.

The objective of Phase III is to develop an engineering design package and a financing plan for an EECP located at the Motiva Refinery in Port Arthur, Texas.

The project's intended result is to provide the necessary technical, economic, and environmental information that will be needed to move the EECP forward to detailed design, construction, and operation by industry.

This report covers all of the subject areas stated in the DOE Cooperative Agreement Statement of Work. It addresses in detail the eight tasks specified and outlines the results, discussions, and conclusions derived from the work performed in each of the areas. The report also recommends areas that we feel need further study in Phase II. 


\section{TABLE OF CONTENTS}

BOOK 1

Section

Description

Page

Book Cover

Transmittal Letter

Title Page

Disclaimer

Abstract

Table of Contents

List of Tables, Figures and Drawings

Executive Summary

Experimental

Results and Discussion

Conclusion

References

List of Acronyms

i

ii

iii

TFD-1

ES-1

E-1

RD-1

C-1

R-1

A-1

\section{TASK 1}

\section{0}

PROJECT PLAN

1-1

1.1

Project Management Plan

1-1

1.1 .1

1.1 .2

1.1 .3

1.1 .4

1.1 .5

Work Breakdown Structure

$1-1$

Schedule and Milestones

$1-1$

Manning and Project Cash Flow Projections

$1-1$

DOE Review

Final Issue

$1-1$

$1-2$

\section{TASK 2}

\section{0}

CONCEPT DEFINITION, DEVELOPMENT, AND TECHNICAL ASSESSMENT

2.1

2.1.1

2.1 .2

2.1.2.1

2.1.2.2

2.1.2.3

2.1 .3

2.1.3.1

2.1.3.2

2.1.3.3

2.1.3.4

2.1.3.5

2.1.3.5.1

2.1.3.5.2

2.1.3.5.3
Overview

Overall Concept Definition and Development

Market

Technical

F-T Product Upgrading Options

F-T Catalyst Wax Separation

F-T Wastewater Treating/Utilization

Economics/Optimizations

F-T Feed Gas $\mathrm{H}_{2}$ :CO Optimum Ratio

Heat and Process Integration

Percent of $\mathrm{CO}_{2}$ in the F-T Feed Gas

Acid Gas Removal Scheme

F-T Tail Gas Utilization Study

Reactors in Series

Recycle to the F-T Reactor

Recycle to the Syngas Generation Unit
2-1

$2-2$

$2-2$

$2-4$

2-4

2-6

2-6

2-7

$2-8$

2-9

2-10

2-11

2-11

2-12

2-12

2-12 


\section{Section}

2.1.3.5.4

2.1.3.5.5

2.1.3.5.6

2.2

2.2.1

2.2.2

2.2.2.1

2.2.2.1.1

2.2.2.2

2.2.2.3

2.2.2.3.1

2.2.2.3.2

2.2.2.3.3

2.2.2.4

2.2.2.5

2.2.2.6

2.2.2.7

2.2.2.8

2.2.2.9

2.2.2.9.1

2.2.2.9.2

2.2.2.9.3

2.2.2.9.4

2.2.2.10

2.2.2.11

2.2.2.11.1

2.2.2.11.2

2.2.2.11.3

2.2.2.11.4

2.2.2.11.5

2.2 .3

2.3

2.3.1

2.3.2

2.3 .3
Description

Page

Fuel for Power Generation

2-13

Other Utilization Options

EECP Concept - Selected Tail Gas Utilization Concept

$2-13$

2-13

$2-13$

2-13

Introduction

Results and Discussion

2-15

Design Basis

2-15

Design Basis - Product Upgrading Summary $\quad 2-23$

Block Flow Diagrams $\quad 2-28$

Process Descriptions $2-33$

Overall Block Flow Diagram 2-33

Port Arthur Cases - PARHCU and PARFW 2-33

Tampa Electric Polk Station Cases - THCU and TSC 2-35

$\begin{array}{lr}\text { Stream Summaries } & 2-37\end{array}$

Equipment List $\quad 2-62$

Overall Utility Summaries $\quad 2-74$

Heat and Process Integration $\quad 2-79$

Acid Gas Removal Options $\quad 2-80$

Capital Cost Estimate $\quad 2-81$

Purpose and Scope $\quad 2-81$

Approach $\quad 2-82$

Estimate Structure $\quad 2-82$

Methodology $2-83$

Environmental Considerations $\quad 2-87$

Marketing Considerations $\quad 2-88$

Plant Site Selection Criteria $\quad 2-88$

Objectives $2-88$

Background Information $\quad 2-88$

Product Slate and Pricing $\quad 2-89$

Product Valuation Methodologies $\quad 2-90$

Conclusions $2-94$

Design Considerations for Advanced Subsystems 2-98

Fischer-Tropsch Synthesis $\quad 2-99$

Gas Turbine $\quad$ 2-102

Fischer-Tropsch Product Upgrading 2-105

\section{TASK 2 - ATTACHMENTS}

2-A Attachment 2-A: F-T Product Upgrade Options Study 2A-1

2-B Attachment 2-B: F-T Wastewater Treating/Utilization Study 2B-1

2-C Attachment 2-C: F-T Feed Gas $\mathrm{H}_{2}$ :CO Optimum Ratio Study 2C-1

2-D Attachment 2-D: F-T Feed Gas Optimum Percent $\mathrm{CO}_{2}$ Study 2D-1

2-E Attachment 2-E: Acid Gas Removal Selection Study 2E-1

2-F Attachment 2-F: Evaluation of a Combined Primary and Tail Gas 2F-1

Treating Amine System 
Section

Description

Page

TASK 3

\section{0}

TECHNICAL ASSESSMENT OF SUBSYSTEMS

3.1

Overview

Basic Engineering Design Data 3-2

3.2

Air Separation Unit

3-3

Process Arrangement

3-3

Design Basis $3-3$

3.2 .2

Gasification

3-9

3.4

Acid Gas Removal

3-11

3.4 .1

Stripping Nitrogen

3-11

3.5

Sulfur Recovery Unit/Tail Gas Treating Unit

3-13

3.6

Fischer-Tropsch Synthesis

3-15

3.6 .1

Battery Limit Conditions

3-15

3.6 .2

Syngas

3-16

3.6 .3

Zinc Oxide Bed Design Basis

3-17

3.6 .4

3.6 .5

3.6 .6

Fischer-Tropsch Synthesis Reactor Yields

3-17

Fischer-Tropsch Catalyst Properties

3-17

Catalyst Activation

3-17

Gas Turbine/Generator

3-18

3.8

Steam System

3-22

3.8 .1

Steam System Header Pressure

3-22

3.8 .2

3.8 .3

3.9

Steam Condensate Systems

3-22

Water Systems

$3-22$

Fischer-Tropsch Product Upgrading 3-23

3.9 .1

Scope of Work

3-23

3.9 .2

3.9 .3

Feedstock and Product Properties

3-24

Feed Rates and Process Yields $\quad 3-29$

3.9 .4

3.9 .5

Hydrogen Make-Up Gas

$3-29$

Unit Design Basis

3-30

3.9.5.1

3.9.5.2

3.9 .6

3.9 .7

Service Factor

3-30

Design Considerations $\quad 3-30$

Battery Limit Conditions

3-31

Unit Turn-Down

3-31

Off Site

3-31

3.10 .1

Purge Nitrogen

3-31

3.10 .2

Flare System

3-32

3.10 .3

Secondary Fuel Specifications

3-32

3.10 .4

Plant and Instrument Air

3-33

3.10 .5

Electric Power

3-33

3.10 .6

Cooling Water

3-34

3.11

Unit/Equipment Numbering

3-35 
BOOK 2

Section

Description

Page

TASK 4

4.0 SUBSYSTEM DESIGN SPECIFICATIONS

Overview

4-1

4.1

EECP Concept

4-2

4.1 .1

Concept Process Description

4-2

4.1 .2

Overall Block Flow Diagrams

4-4

4.1 .3

Refinery Integration

4-9

4.1 .4

Pinch Analysis

4-10

4.2

Process Description

4-10

4.2 .1

Air Separation Unit

4-10

4.2.1.1

Gas Turbine Extraction Air Supply

4-11

4.2.1.2

Main Air Feed Filtration and Compression

4-11

4.2.1.3

Air Cooling and Purification

4-11

Cryogenic Distillation

4-11

Product Compression

4-12

Gasification

4-12

Coke Handling Unit (U-2000)

4-12

Slurry Preparation Unit (U-3000)

4-12

Gasification Unit (U-4000)

4-13

Coarse Slag Handling Unit (U-5000)

4-13

Black Water Flash Unit (U-6000)

4-13

Fines Handling Unit (U-7000)

4-14

Low Temperature Gas Cooling (U-8000)

4-14

Acid Gas Removal Unit

4-14

Fischer-Trospch Synthesis

4-15

Fischer-Tropsch Reactor

4-15

4.2.4.1

4.2.4.2

F-T Product Separation

4-15

4.2.4.3

F-T Reaction Heat Removal System

4-16

4.2.4.4

4.2 .5

Catalyst Handling System

4-16

F-T Upgrading

4-17

General

4-17

4.25 .2

Description of Flow

4-18

4.2 .6

Power Block

4-20

4.2.6.1

Gas Turbine

4-21

4.2.6.2

Steam Turbine

4-22

4.2.6.3

4.2.6.4

4.2.6.5

Generators

4-22

Heat Recovery Steam Generator $\quad$ 4-22

4.2.6.6

4.2 .7

Unit Controls

4-23

Feedwater System

4-23

SRU/TGTU Process Description

4-23

4.2 .8

4.2 .9

Steam System Process Description

4-24

Off Site

4-25

4.3

Process Flow Sketches

4-26

4.3.1

Air Separation Unit

4-26

4.3.2

Gasification Unit

4-26

4.3.3

Acid Gas Removal Unit

4-26

DOE Cooperative Agreement No. DE-FC26-99FT40658 


\section{Section}

Description

Page

4.3.4

F-T Synthesis Unit

4-26

4.3 .5

F-T Upgrading Unit

4-26

4.3.6

Power Block Unit

4-26

4.3.7

Sulfur Recovery Unit/Tail Gas Treating Unit

4-26

4.3.8

Steam System

4-27

Off Site

4-27

4.3.10

Power Distribution Network

4-27

Stream Summaries

4-50

ASU Stream Summaries

4-50

Gasification

4-51

Acid Gas Removal

4-54

F-T Synthesis

4-54

F-T Upgrading

4-65

Power Block

4-66

SRU/TGTU

4-68

Equipment List

4-70

ASU

4-70

Gasification

4-70

AGR

4-73

F-T Synthesis

4-74

F-T Product Upgrading Equipment List

4-75

Power Block

4-77

SRU/TGTU

4-77

Steam System Equipment List

4-78

Off Site Equipment List

4-79

Utility/Catalyst/Chemical Summary

4-80

ASU

4-83

Gasification

4-83

AGR

4-86

F-T Synthesis

4-87

F-T Upgrading

4-91

Power Block

4-92

SRU/TGTU

4-92

Steam System

4-95

4.6 .8

Off Site

4-95

4.6.10

Overall Utility Plan

4-95

4.7

Subsystem Plot Plans

4-96

4.7.1

Overall Plot Plan

4-96

4.7 .2

Air Separation Unit

4-96

4.7.3

Gasification

4-96

AGR

4-96

4.7 .5

F-T Synthesis

4-96

4.7.6

F-T Upgrading

4-96

Power Block

4-96

4.7 .8

SRU/TGTU/AGR

4-96

4.8

Technical Barriers

4-105

F-T Synthesis

4-105

4.8.1.1

Reactor Design Concerns

4-106

4.8.1.1.1

Confirmation of Catalyst Performance

4-106

4.8.1.1.2

Catalyst Replacement Rate

4-107 


\section{Section}

4.8.1.1.3

4.8.1.1.4

4.8.1.1.5

4.8.1.1.6

4.8.1.2

4.8.1.2.1

4.8.1.2.2

4.8.1.3

4.8.1.3.1

4.8.1.3.2

4.8.1.3.3

4.8.1.4

4.8.1.4.1

4.8.1.4.2

4.8.1.4.3

4.8 .2

4.8.3

4.8.3.1

4.8.3.1.1

4.8.3.1.2

4.8.3.1.3

4.8.3.1.4

4.8.3.1.5

4.8.3.2

4.8 .4

4.8 .5

4.8.5.1

4.8.5.2

4.8.5.3

4.8.5.4

4.8.5.5
Description

Page

Water Gas Shift Activity

4-107

Hydrodynamics

4-107

4-108

Design of Reactor Internals

4-109

Catalyst/Wax Separation

4-109

Rentech Primary Separation

4-109

4-110

4-110

4-110

4-110

4-110

4-111

4-111

4-111

4-112

4-112

4-112

4-114

4-115

4-115

4-115

4-116

4-116

4-117

4-118

4-119

4-120

4-120

4-121

4-122

4-122

\section{TASK 4 - ATTACHMENTS}

4-A Attachment A: Pinch Analysis

4-B Attachment B: Facilities Reliability Study

\section{TASK 5}

\subsection{MARKET ASSESSMENT $\quad$ 5-1}

Market Analysis of Products

5.1.1 Diesel 5-1

5.1.1.1 Current Market Size 5-1

5.1.1.2 Supply and Demand $5-2$

5.1.1.3 Projected 10-Year Growth Rates 5-2

5.1.1.4 Current Prices 5-2

5.1.1.5 Projected 10-Year Prices 5-3

5.1.1.6 Projected New Markets 5-3 
Section

5.1 .2

5.1.2.1

5.1.2.2

5.1.2.3

5.1.2.4

5.1 .2 .5

5.1.2.6

5.1 .3

5.1.3.1

5.1.3.2

5.1.3.3

5.1.3.4

5.1.3.5

5.1.3.6

5.1 .4

5.1.4.1

5.1 .4 .2

5.1 .4 .3

5.1.4.4

5.1 .5

5.1.5.1

5.1.5.2

5.1.5.3

5.1.5.4

5.1.5.5

5.1.5.6

5.2

5.2.1

5.2 .2

5.2 .3

5.3

5.3.1

5.3 .2

5.3 .3

5.3 .4

5.4

5.4 .1

5.4 .2

5.4 .3

5.4 .4

Finished Waxes

Description

Page

Current Market Size

5-3

Supply and Demand

5-4

Projected 10-Year Growth Rates

5-4

Current Prices

$5-4$

Projected 10-Year Prices

$5-4$

Projected New Markets

5-5

F-T Naphtha

5-5

Current Market Size

5-6

Supply and Demand

5-6

Projected 10-Year Growth Rates

5-6

Current Prices

5-6

Projected 10-Year Prices

5-7

Projected New Markets

5-7

Power

$5-8$

Current Market Size

$5-8$

Supply and Demand

$5-8$

Projected 10-Year Growth Rates

$5-8$

EECP Electrical Power Price

$5-8$

Sulfur

$5-9$

Current Market Size

$5-9$

Supply and Demand

$5-9$

Projected 10-Year Growth Rates

$5-9$

Current Prices

5-10

Projected 10-Year Prices

5-10

Projected New Markets

5-10

Market Assessment of Technology

Feedstock Availability

5-11

Environmental Factors

5-11

Technology Factors

5-12

Fischer-Tropsch Product Slate and Analysis

5-12

Diesel

5-15

5-15

Naphtha

5-16

Specialty Low and Medium Melt Waxes

$5-18$

Specialty High Melt Waxes

5-19

Full-Scale Commercial Plant

$5-20$

Price and Feedstock Availability

$5-20$

Proximity to Markets

$5-21$

Environmental Considerations

5-21

Infrastructure and Process Integration

$5-22$

\section{TASK 6}

6.0 PRELIMINARY SITE ANALYSIS

6-1

Overview

6-1

6.1

Site Selection Process

6-1

6.1 .1

Synergy with Existing Infrastructure

6-1

6.1 .2

Construction Requirements

6-1

6.1 .3

Site Access

6-4 
Section

6.1 .4

6.1 .5

6.1 .6

6.1 .7

6.1 .8

6.2

6.3

TASK 7

\section{0}

ENVIRONMENTAL ASSESSMENT

Overview

Description

Page

Environmental Requirements

6-4

Community

Geotechnic and Topographic Investigation

6-4

6-4

Economic Factors

Site Commitment to Project

6-4

6-4

6-4

Identify Additional Commitments/Parties for EECP Participation

7-1

7.1

Summary

NEPA Requirements

7.1 .1

Air Permit Requirements

Wastewater Permit Requirements

Solid Waste Permit Requirements

Emission Levels

Adaptability for $\mathrm{CO}_{2}$ Sequestration

$7-1$

7.1 .2

7.1 .3

7.1 .4

7.2

7.3

7.3.1

7.3.1.1

7.3.1.2

7.3 .2

7.3.2.1

7.3.2.2

7.3.2.3

7.3.2.4

7.3.2.5

7.3.2.6

7.3 .3

7.3.3.1

7.3.3.2

7.3.3.3

7.3.3.4

7.3.3.5

7.4

7.5

Introduction

$\mathrm{CO}_{2}$ Emissions for EECP Phase I Project

$7-1$

EECP Adaptability for $\mathrm{CO}_{2}$ Sequestration

$7-1$

Sequestration Options

$7-2$

Membrane Contactor

$7-2$

Kerr-McGee/ABB Lummus $\mathrm{CO}_{2}$ Recovery Technology

$7-2$

Mitsubishi Heavy Industries, Ltd. Technology

Membranes

$7-6$

Carbon Fiber Composite Molecular Sieve

Others

$\mathrm{CO}_{2}$ Sequestration

7-6

$7-6$

7-6

7-7

7-7

$7-7$

7-8

$7-8$

$7-8$

$7-8$

$7-9$

Chemical Utilization of $\mathrm{CO}_{2}$

$7-9$

Enhanced Oil Recovery

$7-9$

$\mathrm{CO}_{2}$ Storage

$7-9$

Advanced Concepts

$7-10$

Forestation

7-10

Water Use and Remediation

7-11

Solid Waste Byproducts

7-11

NEPA Requirements

$7-12$

7.6

7.7

7.7.1

7.7.1.1

Permitting Requirements

7-13

Air

$7-13$

Permit to Construct

$7-13$

7.7.1.2

Non-Attainment Review

7-14

7.7.1.3

Prevention of Significant Deterioration Review

$7-16$

7.7 .2

Wastewater

7-16

7.7 .3

7.7.3.1

Solid Waste

$7-17$

Non-Hazardous Wastes $\quad$ 7-17

7.7 .3 .2

Hazardous Wastes

7-17

Integration of Existing Facilities with New Treatment Facilities

7-17

7.8

Wastewater Treatment

7-17 
Section

Description

Page

7.8.2 Solid Waste Disposal

\section{TASK 8}

8.0 ECONOMIC ASSESSMENT

Overview 8-1

8.1 Feedstock Cost and Product Price Evaluation 8-2

8.1.1 Economic Parameters 8-4

8.1.2 Economic Sensitivity Analysis 8-4

8.1.3 Taxes, Royalties, and Inflation 8-4

8.2 Cost Estimates 8-5

8.2.1 Capital Estimates Methodology 8-5

8.2.2 Operating Costs 8-11

8.2.3 Refinery Site Maintenance 8-12

8.3 Role of Government Incentives for Commercial Viability of EECP 8-13

8.3.1 Tax Relief 8-13

8.3.2 Energy Policy Act (EPACT) Alternate Fuels 8-14

8.3.3 Long-Term F-T Liquids Purchase Agreement 8-14

8.3.4 Cost Sharing 8-14 


\section{LIST OF TABLES, FIGURES \& DRAWINGS}

\section{TABLES}

Number

Description

Page

$\mathrm{RD}-1$

$\mathrm{RD}-2$

RD-3

2.1.1-1

2.1.3-1

2.2.2-1

2.2.2-2

2.2.2-3

2.2.2-4

2.2.2-5

2.2.2-6

2.2.2-7

2.2.2-8

2.2.2-9

2.2.2.10

2.2. $2-11$

2.2. $2-12$

2.2. $2-13$

2.2. $2-14$

2.2. $2-15$

2.2.2-16

2.2.2-17

2.2. $2-18$

2.2. $2-19$

2.2. $2-20$

2.2.2-21

2.2.2-22

2.2. $2-23$

2.2. $2-24$

2.2. $2-25$

2.2.2-26

2.2.3-1

3.1-1

3.2.1-1

3.2.1-2

3.2.1-3

3.2.1-4
Site Selection Criteria

Cases Considered

Summary of EECP Economic Model Results

Coke Production

Percentage Discounted Case Flow Rates

Feed, Gas Turbine Fuel, and Product Comparison

Design Basis - Motiva Port Arthur Refinery

Design Basis - Tampa Polk Power Station

Upgrading Unit Feedstock Properties

Upgrading Unit Product Yields

Upgrading Unit Product Properties

Reactor Section Operating Conditions

Utility Conditions

Material Balance - PARHCU Case (SI Units)

Material Balance - PARHCU Case (English Units)

Material Balance - PARFW Case (SI Units)

Material Balance - PARFW Case (English Units)

Material Balance - TSC Case (SI Units)

Material Balance - TSC Case (English Units)

Material Balance - THCU Case (SI Units)

Material Balance - THCU Case (English Units)

Overall Utility Summary - PARHCU (SI Units)

Overall Utility Summary - PARHCU (English Units)

Overall Utility Summary - PARFW (SI Units)

Overall Utility Summary - PARFW (English Units)

Overall Utility Summary - THCU (SI Units)

Overall Utility Summary - THCU (English Units)

Overall Utility Summary - TSC (SI Units)

Overall Utility Summary - TSC (English Units)

Cost Summary for Each Case

Cost Summary for One-Year Operation

Summary of EECP Economic Model Results

PAR Design Data

ASU Design Basis: GT Extraction Air to ASU, Oxygen and Nitrogen Products (SI Units)

ASU Design Basis: Purge Nitrogen, Plant Air, Instrument Air Products (SI Units)

ASU Design Basis: GT Extraction Air to ASU, Oxygen and Nitrogen Products (English Units)

ASU Design Basis: Purge Nitrogen, Plant Air, Products (English Units)
$\mathrm{RD}-2$

$\mathrm{RD}-6$

RD-8

2-3

2-9

2-16

2-17

2-20

2-24

2-25

2-26

2-27

2-27

2-38

2-41

2-44

2-47

2-50

2-53

2-56

2-59

2-75

2-75

2-76

2-76

2-77

2-77

2-78

2-78

2-85

2-86

2-97

3-2

3-5

3-6

3-7

3-8 
Number

3.3-1

3.4-1

3.4.1-1

3.5-1

3.6.1-1

3.6.1-2

3.6.1-3

3.6.2-1

3.6.3-1

3.6.4-1

$3.7-1$

$3.7-2$

$3.7-3$

$3.7-4$

$3.7-5$

$3.7-6$

$3.7-7$

3.7-8

3.7-9

3.7-10

3.7-11

3.7-12

3.8.1-1

3.8.1-2

3.9.2-1

3.9.2-2

3.9.2-3

3.9.2-4

3.9.3-1

3.9.3-2

3.9.4-1

3.9.6-1

3.10.1-1

3.10.3-1

3.10.4-1

3.10.4-2

3.10.5-1

3.10.6-1

3.11-1

3.11-2

3.11-3

3.11-4

$3.11-5$

4.4.1-1

4.4.1-2

4.4.2-1

4.4.2-2
Description

Page

Gasification Design and Operating Conditions

3-9

Acid Gas Removal Data

Stripping Nitrogen Rates

SRU/TGTU Design and NOC Data

Feed Streams Entering F-T Synthesis Plant

Product Streams Leaving F-T Synthesis Plant

Effluent Streams

Syngas Components

Design Basis for Zinc Oxide Bed

3-11

3-12

3-13

3-15

3-15

3-16

3-16

3-17

F-T Synthesis Reactor Yields $3-17$

Design Basis $\quad$ 3-18

GT Primary Fuel (Syngas, AGR Offgas and F-T Tail Gas) 3-19

GT Start-Up Fuel (Natural Gas)

Head-End Diluent Injection

3-19

3-19

Equivalent LHV (Fuels + Diluent)

$3-20$

Exhaust Analysis (Normal Operation)

$3-20$

Emissions (Normal Operation)

$3-20$

Gas Turbine Auxiliaries (Normal Operation)

3-20

Start-Up Requirements

3-21

Instrument Air

3-21

3-21

Shutdown Requirements

$3-21$

Cooling Water (for Gas Turbine and TEWAC Generator)

$3-22$

Steam Production Blocks

$3-22$

$3-25$

$3-26$

$3-27$

$3-28$

$3-29$

$3-29$

3-30

3-31

3-32

$3-32$

$3-33$

3-33

EECP Process Blocks Instrument and Plant Air NOC

Requirements

Electric Power Data

3-34

Cooling Water Specifications $\quad$ 3-34

Unit Numbering Conventions $\quad 3-35$

Equipment Designation Conventions 3-36

SI and English Unit Conventions $\quad 3-37$

Abbreviations and Codes

$3-38$

3-39

$4-50$

4-51

$4-52$

4-53 
Number

4.4.3-1

4.4.3-2

4.4.4-1

4.4.4-2

4.4.5-1

4.4.5-2

4.4.6-1

4.4.6-2

4.4.7-1

4.4.7-2

4.5.1-1

4.5.2-1

4.5.3-1

4.5.4-1

4.5.5-1

4.5.5-2

4.5.6-1

4.5.7-1

4.5.9-1

4.6-1

4.6.1-1

4.6.2-1

4.6.2-2

4.6.3-1

4.6.4-1

4.6.4-2

4.6.5-1

4.6.6-1

4.6.7-1

4.6.7-2

4.8.5-1

5.1.1-1

5.1.1-2

5.1.2-1

5.1.2-2

5.1.3-1

5.1.3-2

5.3.2-1

5.3.2-2

5.3.3-1

5.3.4-1

6.1-1

6.2-1
Description

Stream Summary - Unit 9000 Acid Gas Removal (SI Units)

Page

Stream Summary - Unit 9000 Acid Gas Removal (English Units) 4-56

Stream Summary - Unit 10000 F-T Synthesis (SI) 4-57

Stream Summary - Unit 10000 F-T Synthesis (English) 4-61

Feed Properties

Product Properties

4-65

4-65

Power Block Stream Summary for Motiva Port Arthur Refinery 4-66

(SI Units)

Power Block Stream Summary for Motiva Port Arthur Refinery

$4-67$

(English Units)

SRU/TGTU Stream Summary (SI Units)

4-68

SRU/TGTU Stream Summary (English Units) 4-69

Air Separation Unit (ASU-1000) Major Equipment List 4-70

Gasification Equipment List - Unit 2000-8000 4-71

AGR Unit Equipment List

4-73

4-74

Equipment List - Unit 10000

ISBL Equipment

4-75

4-76

4-77

4-77

4-79

4-80

$4-83$

4-84

4-85

$4-86$

$4-87$

4-89

4-91

4-92

4-93

4-94

4-119

$5-2$

$5-3$

$5-4$

$5-5$

$5-7$

$5-7$

$5-17$

$5-18$

5-19

$5-19$

Expected Wax Finished High Melt Wax Grade

Product Properties

Site Selection Criteria

$6-2$

Summary of EECP Economic Model Results

6-6 
7.2-1

$7.2-2$

7.5-1

7.7.1-1

Estimated Emissions (SI Units)

7-3

Estimated Emissions (English Units)

7-4

Solid Waste Summary

$7-11$

Major Source/Major Modification Emission Thresholds

7-15

7.7.1-2 (SI Units)

7-15 (English Units)

8.1.1-1

8.2.1-1

EECP Project Variables

8-5

8.2.2-1 Capital Cost Estimate

8-10

Operating Staffing Levels

8-12

Administrative Personnel Staffing

8-12

8.2.2-2

Routine Maintenance Staffing

8-13 


\section{FIGURES}

\section{Number}

$\mathrm{RD}-1$

$\mathrm{RD}-2$

RD-3

2.1.2-1

2.1.2-2

2.1.3-1

2.1.3-2

2.2.2-1

2.2.2-2

2.2.2-3

2.2.2-4

$3.11-1$

4.1.2-1

4.1.2-2

4.1.2-3

4.1.2-4

4.2.2.5

4.3.1-1

4.3.2-1

4.3.2-2

4.3.2-3

4.3.2-4

4.3.2-5

4.3.2-6

4.3.2-7

4.3.3-1

4.3.4-1

4.3.4-2

4.3.4-3

4.3.5-1

4.3.5-2

4.3.6-1

4.3.7-1

4.3.7-2

4.3.8-1

4.3.8-2

4.3.9-1

4.3.9-2

4.3.10-1

4.7.1-1
CO Conversion as a Function of $\mathrm{CO}_{2}$ in the Feed

Hydrocarbon Yields as a Function of $\mathrm{CO}_{2}$ in the Feed

Overall Block Flow Diagram

Capital Cost (+/- 50\%)

Product Valuation

$\mathrm{CO}$ Conversion as a Function of $\mathrm{CO}_{2}$

Hydrocarbon Yields as a Function of $\mathrm{CO}_{2}$

Overall Block Diagram - PARHCU (Motiva Port Arthur

Refinery Hydrocracking Case)

Overall Block Flow Diagram - PARFW (Motiva Port

Arthur Refinery Finished Wax Case)

Overall Block Flow Diagram - THCU (Tampa Electric

Hydrocracking Case)

Overall Block Flow Diagram - TSC (Tampa Electric

Syncrude Case)

Equipment Numbering System Conventions

3-40

Overall Block Flow Diagram

4-5

Block Flow Diagram with Process Streams (SI)

4-6

Block Flow Diagram with Process Streams (English) 4-7

EECP Project Cycle Efficiency Summary (SI Units) 4-8

EECP Project Cycle Efficiency Summary (English Units) 4-9

Air Separation Unit

Coke Handling Unit (Gasification)

Slurry Preparation Unit (Gasification)

Gasification and Syngas Scrubbing Unit

Coarse Slag Handling Unit (Gasification)

Black Water Flash Unit (Gasification)

Fines Handling Unit (Gasification)

Low-Temperature Gas Cooling Unit (Gasification)

Acid Gas Removal

F-T Reaction Section

F-T Product Section

F-T Catalyst Handling

F-T Upgrading - Feed and Reaction Section

F-T Upgrading - Product Recovery Section

Power Block

SRU/TGTU - Sulfur Recovery Unit

SRU/TGTU - Tail Gas Treating Unit

NOC - Steam System (SI Units)

NOC - Steam System (English Units)

NOC - Cooling Water System (SI Units)

$4-28$

4-29

4-30

4-31

4-32

4-33

4-34

4-35

4-36

4-37

4-38

4-39

4-40

4-41

4-42

4-43

4-44

4-45

4-46

4-47

NOC - Cooling Water System (English Units) 4-48

Power Distribution Network

4-49

4-97 
Number

Description

Page

4.7.2-1

ASU Plot Plan

4-98

4.7.3-1

Gasification and AGR Plot Plan

4-99

4.7.4-1

Gasification and AGR Plot Plan

4-99

4.7.5-1

F-T Synthesis Plot Plan

4-100

4.7.6-1

4.7.6-2

4.7.7-1

F-T Upgrading - Outside Battery Limits

4-101

F-T Upgrading - Inside Battery Limits

4-102

Power Block Plot Plan

4-103

4.7.8-1

SRU/TGTU/AGR Stripper Plot Plan

4-104

Case A: Percentage of Shutdown Hours

4-120

4.8.5-1

4.8.5-2

4.8.5-3

Case B: Percentage of Shutdown Hours

4-121

Case C: Power Island Total Hours

4-122

5.1.4-1

5.1.4-2

Cumulative 10-Year Power Growth Rate, \%

$5-8$

Electrical Rates - Basis 1998\$

$5-9$

Projected World Petroleum Coke Production to 2010

5-12

8.0-1

Output Sheet

8-3

8.1.2-1

EECP Expected Value Curve

8-6

8.1.2-2

Project's Sensitive Variables

8-7

8.1.2-3

EECP Decision Tree

8-8 


\section{DRAWINGS}

\section{Number}

KBR-P-BFD-0001

KBR-P-BFD-001

KBR-P-BFD-002

KBR-T-BFD-001

KBR-T-BFD-002

KBR-P-BFD-0001

KBR-P-BFD-0002S

KBR-P-BFD-0002E

PX-P-PFS-1000

TX-P-PFS-2000

TX-P-PFS-3000

TX-P-PFS-4000

TX-P-PFS-5000

TX-P-PFS-6000

TX-P-PFS-7000

TX-P-PFS-8000

TX-P-PFS-9000

TX-P-PFS-10100

TX-P-PFS-10200

TX-P-PFS- 10300

TX-P-PSK-11001

TX-P-PSK-11002

GE-P-PFS-12001

TX-P-PFS-15000

TX-P-PFS-15100

KBR-P-PFD-0001

KBR-P-PFD-0001

KBR-P-PFD-0002

KBR-P-PFD-0002

KBR-P-PFD-0003

TX-P-PLOT-0000

PX-P-PLOT-1000

TX-P-PLOT-2000

TX-P-PLOT-10000

TX-P-PLOT-11002

TX-P-PLOT-11001

GE-P-PLOT-12001

TX-P-PLOT-15000

\section{Description}

Page

Overall Block Flow Diagram

RD-18

Block Flow Diagram - Case: PARHCU

2-29

(Hydrocracking)

Block Flow Diagram - Case: PARFW

$2-30$

(Finished Wax)

Block Flow Diagram - Case: THCU

$2-31$

(Hydrocracking)

Block Flow Diagram - Case: TSC

(Syncrude Dewaxing)

Overall Block Flow Diagram

4-5

Block Flow Diagram with Process Streams (SI)

4-6

Block Flow Diagram with Process Streams (English)

4-7

Air Separation Unit - Unit 1000

4-28

Coke Handling Unit - Unit 2000

4-29

4-30

4-31

4-32

4-33

4-34

4-35

4-36

4-37

4-38

4-39

4-40

Fischer-Tropsch Product Upgrading - Feed and

Reaction Section

Fischer-Tropsch Product Upgrading - Product

4-41

Recovery Section

Power Block Process Flow Sketch

4-42

Sulfur Recovery Unit - 15000

Tail Gas Treating Unit - 15000

NOC - Steam System (SI Units)

NOC - Steam System (English Units)

NOC - Cooling Water System (SI Units)

NOC - Cooling Water System (English Units)

NOC - Power Balance

Overall Plot Plan

ASU Plot Plan - 1000

Gasification AGR Section

4-43

4-44

4-45

4-46

4-47

4-48

4-49

4-97

4-98

4-99

F-T Synthesis Unit Plot Plan $\quad 4-100$

F-T Upgrading - Outside Battery Limits 4-101

F-T Upgrading - Inside Battery Limits 4-102

Power Block Plot Plan 4-103

SRU/TGTU/AGR Stripper Plot Plan 4-104 


\section{EXECUTIVE SUMMARY}

This document is the Concept Report for Phase I of the Early Entrance Coproduction Plant (EECP) Project, which is covered by Cooperative Agreement No. DE-FC2699FT40658 and is part of DOE's "Vision 21" initiative. The objective of this project is the three-phase development of a coproduction plant that produces at least one product from at least two of the following three categories: (1) electric power (or heat), (2) fuels, and (3) chemicals. The objective is to have these products produced by technologies capable of using synthesis gas derived from coal and/or some other carbonaceous feedstock, such as petroleum coke. The objective of Phase I was to determine the feasibility and define the concept for the EECP located at a specific site and to develop a Research, Development, \& Testing (RD\&T) Plan for implementation in Phase II. Phase I was completed during December 2000. The objective of Phase II is to conduct the research as outlined in the Phase I RD\&T Plan to enhance the development and commercial acceptance of coproduction technology that produces high-value products, particularly those that are critical to our domestic fuel and power requirements. The project will help resolve critical knowledge and technology gaps on the integration of gasification and downstream processing to coproduce some combination of power, fuels, and chemicals. Phase II is scheduled for two calendar years (2001 through 2002). Phase III is scheduled for calendar year 2003 and its objective is to develop an engineering design package and a financing plan for the EECP. The overall project's intended result is to provide the necessary technical, economic, and environmental information needed to move the EECP forward to detailed design, construction, and operation by industry.

A consortium, comprised of representatives from Texaco, Inc.; Kellogg Brown \& Root, Inc.; General Electric Power Systems; Praxair, Inc.; and Rentech, Inc., was formed to undertake this work. Texaco provided the overall project management as well as conceptual design for the Gasification, Acid Gas Removal, Sulfur Recovery, and the Tail Gas Treating Units of the facility. Kellogg Brown \& Root provided engineering/technical services; General Electric provided combined cycle technology; Praxair provided air separation technology; and Rentech provided Fischer-Tropsch synthesis technology. Bechtel, under separate contract with Texaco, provided Fischer-Tropsch product upgrading technology for producing finished wax.

The proposed EECP will coproduce electric power, steam, clean fuels, and finished wax using petroleum coke as the source material. Petroleum coke was selected as the feedstock because it would be the lowest cost source of hydrogen and carbon for the future and the highest probable application of the EECP concept. We believe that the demonstration with petroleum coke will prove the concept, since coal is generally more reactive than coke due to the differences in the molecular structures. The higher volatility of coal, due to the relative ease of its thermal cracking, is perhaps the most obvious difference and is the source of many of the process differences seen. This position is based on gasification pilot plant research and development results for over fifty years of using different feedstocks and their performance in the gasification process. Feedstocks have included petroleum products ranging from natural gas to the heaviest petroleum fractions, petroleum coke, and coal ranging from anthracite to lignite and many types of waste materials. In the EECP concept, approximately 1,235 short tons per day (STPD) of petroleum coke is fed into a Texaco gasifier along with oxygen produced from a Praxair Air Separation Unit (ASU). Inside the gasifier, reactions take place at 
very high temperatures, around $1650 \mathrm{~K}\left(2500^{\circ} \mathrm{F}\right)$, which produce synthesis gas, also known as syngas, a mixture of mainly hydrogen and carbon monoxide, with lesser amounts of water vapor, carbon dioxide, hydrogen sulfide, methane, argon, and nitrogen. The syngas is routed to an Acid Gas Removal (AGR) Unit, where virtually all the sulfur compounds are removed along with some carbon dioxide. Roughly $75 \%$ of the cleaned syngas is sent to a General Electric (GE) 6FA gas turbine for power generation. The remainder is routed to a 2.44-meter (8-foot) diameter Fischer-Tropsch (F-T) slurry bubble column reactor (SBCR), where syngas is converted into hydrocarbon liquids. Some unconverted F-T feed gas, along with a light hydrocarbon product produced in the F-T reactor (the combination of which is referred to F-T tail gas), is routed to the gas turbine as fuel for additional power generation. The hydrocarbon liquids are routed to a product upgrading unit to make finished products.

During Phase I, the feasibility of the EECP concept was evaluated by performing process studies and product slate, marketing, economic, and environmental assessments. Site location criteria were developed, and a specific site was selected. As discussed later in the report, two facilities were considered in some detail for the EECP site location. The Motiva Port Arthur, Texas petroleum refinery represented a typical refinery application, and the Tampa Electric Company's Polk Power Generation Station near Tampa, Florida, represented a power generation site. For each site, two cases were developed with differing schemes and product slates. The refinery was ultimately selected for further development as the host site. This selection was based on the economic analysis results attained from a model that provided financial return calculations for 17 different scenarios. The economics favored the Port Arthur "Finished Wax" case over the others primarily due to lower feedstock transportation costs, higher product value, and greater infrastructure compatibility. Further process studies, cost estimates, pro forma calculations, and environmental and economic assessments were developed using that site as the basis. The results are summarized in this document. In addition, a Research, Development, and Testing Plan and a Preliminary Project Financing Plan, documented under separate covers, were developed for implementation in Phase II. 


\section{EXPERIMENTAL}

There were no experimental methods used in accomplishing the Phase I work.

However, in the Phase I write-ups, there are processes discussed that will require further study and probable experimentation during the Phase II work. Some of this experimental work will be accomplished as part of the actions specified in the Research, Development \& Testing Plan. 


\section{Results and Discussion}

\section{Introduction}

This section provides an overview of the work performed in Phase I and includes a discussion for the following areas: feedstock considerations, summary of the site selection process, description of the process studies performed, description of the proposed EECP facility, market assessment, environmental assessment, economic assessment, risk assessment, and technical barriers. More detailed information for each of these areas can be found in the appropriate sections for Tasks 2 through 8.

Conclusions are discussed in the next section.

\section{Feedstock Considerations}

While the original solicitation requested that coal be used as a feedstock, the analysis of the current available feedstocks resulted in our proposal premise that a petroleum coke feedstock would be the best feedstock to enable the EECP concept to become an actual project. The analysis results were that petroleum coke would be the lowest cost source of hydrogen and carbon for the future. The highest probable application of the EECP concept would be on petroleum coke and most probable at a refinery location due to the high cost of handling and transporting petroleum coke to another location. Therefore, our proposal was that the project would be coal capable and therefore must demonstrate that the design would be capable of converting coal to F-T fuel products. This decision was based on gasification pilot plant research and development results for over fifty years of using different feedstocks and their performance in the gasification process. Feedstocks have included petroleum products ranging from natural gas to the heaviest petroleum fractions, petroleum coke, and coal ranging from anthracite to lignite and many types of waste materials. All of these materials have been gasified successfully. Because of the severe operation conditions used in the gasification process, very high temperature and pressure, it has been determined that there are only minor, in many cases negligible, differences in the reactivities of the various feedstocks.

This universality of performance has been further demonstrated in the more than 130 commercial plants that have been built and run using the Texaco Gasification Process. These plants use the complete range of feedstocks, natural gas, all petroleum fractions, asphalt, petroleum coke, coal, and several waste materials. Any differences in the results, such as variations in the composition of the product syngas or thermal efficiency, can be accounted for by the differences in atomic composition of the feedstocks.

Currently, new plants are designed based only on the chemical composition of the feeds.

While this vast store of experience should demonstrate the validity of generalizing gasification performance across feedstocks, some interesting observations have been developed in the cases of petroleum coke and coal. In many other process uses, where operating conditions are less severe, there are significant performance differences. In these cases, coal is generally more reactive than coke because of the differences in the molecular structures. Higher volatility of coal, due to the relative ease of its thermal cracking, is perhaps the most obvious difference and is the source of many of the process differences seen. These processes are generally reaction rate limited at the lower temperatures and pressures used, and the volatiles generated in heating the coal react more rapidly than the solid portions of the material. But in entrained flow 
gasification, reaction rates are extremely high, and primarily physical processes, heat, mass transfer and fluid mechanics determine the performance. When these processes are considered, coal and coke are quite similar and hence, they perform essentially the same in the Texaco Gasification Process.

\section{Summary of Site Selection Process}

Shortly after signing of the DOE Cooperative Agreement, efforts to identify potential EECP host sites began. A site selection team was formed to develop specific site criteria. This team was comprised of representatives from Texaco, Kellogg Brown \& Root, General Electric, and Praxair. Contacts for potential host sites were also identified and asked to provide liaison with the team. The criteria developed, with relative weighting factors, are shown in Table RD-1.

After preliminary discussions with several possible sites, two were identified as having the potential to match up well with the necessary site criteria. One site, Motiva's Port Arthur, Texas Refinery (PAR) was considered representative of a typical petroleum refinery application. The other, Tampa Electric Company's Polk Power Station near Tampa, Florida, was representative of a power generation facility. The site selection team traveled to these two sites to gain a better understanding of the facilities, available infrastructure, and local conditions. Trips were made to Polk Power Station on December 2, 1999, and to the Port Arthur, Texas Refinery on December 7, 1999. These trips confirmed that both sites were suitable for further consideration as the host EECP site. Each facility satisfied many of the criteria considered important to the EECP concept, such as synergy with existing infrastructure, good construction capabilities and site access, similar environmental requirements, good community relations, etc. Further, representatives from both sites exhibited a strong commitment to the EECP concept and were willing to provide the information necessary to the consortium for the conceptual process engineering studies that were to follow.

\section{Table RD-1}

\section{Site Selection Criteria}

\begin{tabular}{|l|}
\hline Site Characteristics (5\%) \\
\hline - Size (20\%) \\
\hline - Elevation (10\%) \\
\hline - Geometry (15\%) \\
\hline - Building and Zoning (10\%) \\
\hline - Flood potential (15\%) \\
\hline - Soil data (10\%) \\
\hline - Seismic Zone (10\%) \\
\hline - Climatic conditions (10\%) \\
\hline \\
\hline Transportation Access (5\%) \\
\hline - River Barges (15\%) \\
\hline - Oceangoing Barges (15\%) \\
\hline - Railroad (20\%) \\
\hline - Highway (20\%) \\
\hline - Pipeline (20\%) \\
\hline - Airport (10\%) \\
\hline
\end{tabular}


Table RD-1

Site Selection Criteria (continued)

\begin{tabular}{|c|}
\hline Pollution Control Regulations (8\%) \\
\hline - Air Emissions (20\%) \\
\hline - Liquid Effluents (20\%) \\
\hline - Water Discharge (20\%) \\
\hline - Solid Waste Disposal (20\%) \\
\hline - Hazardous Waste, Toxic Emissions (20\%) \\
\hline Conservation, Community Factors (6\%) \\
\hline - Terrestrial \& Aquatic Ecology (20\%) \\
\hline * -- Wetlands \\
\hline * -- Endangered species \\
\hline - Obstructions (20\%) \\
\hline * -- Historical Importance \\
\hline * -- Archeological Importance \\
\hline -- Corridor Effects \\
\hline - Local Laws (Noise levels, etc.) (20\%) \\
\hline - Proximity to neighborhoods (20\%) \\
\hline - Proximity to existing reservoir $(20 \%)$ \\
\hline Market Factors (28\%) \\
\hline A. Product Values \& Marketability (Revenue) (35\%) \\
\hline -- Electricity (25\%) \\
\hline -- Steam (25\%) \\
\hline -- F-T Liquid Fuels (25\%) \\
\hline -- Syngas, Hydrogen (15\%) \\
\hline -- Oxygen $(10 \%)$ \\
\hline B. Existing Infrastructure to Supply (35\%) \\
\hline -- Pet coke or coal $(60 \%)$ \\
\hline -- Hydrogen (5\%) \\
\hline -- Oxygen (5\%) \\
\hline -- Nitrogen $(2 \%)$ \\
\hline -- Treated (demineralized) water (3\%) \\
\hline -- Cooling water $(5 \%)$ \\
\hline $\begin{array}{l}\text {-- Existing facilities (bldgs, warehouse, control room, lab, } \\
\text { maintenance shops, storage) (5\%) }\end{array}$ \\
\hline -- Existing process facilities (5\%) \\
\hline -- Existing fire protection, medical $(5 \%)$ \\
\hline -- Existing utilities availability (5\%) \\
\hline C. Existing Infrastructure to Export (30\%) \\
\hline -- Electricity (40\%) \\
\hline -- Steam (10\%) \\
\hline -- F-T Liquid Fuels (15\%) \\
\hline -- Syngas, Hydrogen (25\%) \\
\hline -- Oxygen (10\%) \\
\hline
\end{tabular}


Table RD-1

Site Selection Criteria (continued)

\begin{tabular}{|l|}
\hline Economic Factors \\
\hline A. Capital Cost Factors (15\%) \\
\hline - Land (5\%) \\
\hline - Product pipelines (5\%) \\
\hline - Site Preparation (5\%) \\
\hline -- Foundations \\
\hline -- Grading \\
\hline -- Drainage \& Flood Control \\
\hline -- Dredging \\
\hline - Transportation (rail, road, barges) Access (5\%) \\
\hline - Electric Power Connection (5\%) \\
\hline - Water Supply Treatment (5\%) \\
\hline - Liquid Effluent Disposal (5\%) \\
\hline - Site obstructions removal/relocation (10\%) \\
\hline - Materials Handling/Constructability (15\%) \\
\hline - Skilled construction labor availability \& cost (40\%) \\
\hline \\
\hline B. Operating Cost Factors (13\%) \\
\hline - Raw materials (feedstock, NG, H $) \quad(50 \%)$ \\
\hline - Utilities (power, cooling water, steam, BFW, condensate) \\
\hline (10\%) \\
\hline - Products distribution (5\%) \\
\hline - Raw Water, catalyst, chemicals, other supplies (5\%) \\
\hline - Labor - operations, maintenance (15\%) \\
\hline - Transportation access maintenance (5\%) \\
\hline - Taxes - property, etc. (5\%) \\
\hline - Tax Incentives (5\%) \\
\hline \\
\hline * Site Commitment to Project (20\%) \\
\hline \\
\hline
\end{tabular}

* Possible site elimination category.

The criteria are described as follows:

\section{Synergy with Existing Infrastructure}

The team gave high importance to the possibility of sharing infrastructure, which included facilities and personnel, with the host facility. Infrastructure was divided into two categories: (1) infrastructure to supply items such as feedstock, hydrogen, oxygen, nitrogen, treated water, cooling water, buildings, warehouse, control room, laboratory, maintenance shops, fire protection, medical facilities, utilities, and (2) infrastructure to export products such as electricity, steam, F-T liquid products, syngas, hydrogen, oxygen, etc. The host site's ability to provide infrastructure was considered vital to the success of the EECP concept.

\section{Construction Requirements}

Construction requirements were addressed by the team and included consideration for skilled labor availability and cost, site clearance/preparation, drainage and flood control, 
material handling costs, as well as transportation access. These items would be reflected in the overall facility capital cost estimate.

\section{Site Access}

The team considered feedstock and product shipping requirements as well as site accessibility for delivery of construction equipment and materials. This included consideration of barge, rail, highway, pipeline, and airport accessibility.

\section{Environmental Requirements}

Environmental engineers considered Federal, state, and local environmental regulations for the potential sites. Air emissions, liquid effluents, water discharge, and solid waste disposal were considered. Refer to Section 2.2.2.10 for a description of the environmental considerations.

\section{Community}

The team considered the communities associated with the potential sites including the proximity and type of adjacent neighborhoods, zoning requirements, and the host site's relationship with the community. The team also considered the environmental impact on the community in regard to potential wetlands, endangered species issues, historical or archeological significant areas and noise levels.

\section{Geotechnic and Topographic Investigation}

Consideration for the site included items such as the space available, geometry, elevation, zoning, flood potential, geotechnical and topographical data, seismic zone, and climatic data.

\section{Economic Factors}

Another area considered vital to the success of the concept was capital and operating costs of the EECP. For capital costs, the team made judgements regarding the cost of land, site preparation work, electric power connection, water supply treatment, materials handling, skilled labor availability and cost, and other factors that would ultimately be reflected in total installed cost estimates. Operating costs were also important and consideration was given to feedstock costs, utilities, catalyst/chemicals, product distribution, operating and maintenance labor, taxes, etc.

\section{Site commitment to Project}

The host site's commitment to the EECP Project, by both management and operating personnel, was also judged by the site selection team as vital to successful implementation of the concept.

\section{Process Engineering Studies for Site Selection}

Two EECP concepts were developed for each of the site, for a total of four cases studied. These cases are detailed further in Task 2 of the Concept Report. Generally, the cases differ mainly in the product slate and the F-TPU technology. In the two Port 
Arthur cases, two product upgrading options were developed. In the PARFW case, the F-T liquid is sent to wax finishing unit to produce finished waxes, along with naphtha and diesel. In the PARHCU case, the F-T liquid is sent to a hydrocracking unit, which produces hydrocracked naphtha and diesel. The acid gas generated from the AGR unit is sent to a sulfur plant to make sulfur. In the Port Arthur refinery, steam is exported at different levels.. In the two Tampa cases, two product upgrading options were developed. For the TSC case, the F-T liquid is sent to a Syncrude Dewaxing Unit, where the only hydroprocessing work done is to lower the pour point of the highly waxy F-T liquid. The final product is a single syncrude stream that would be marketed and transported to refineries along the Gulf Coast. For the other Tampa case, THCU, the F-T liquid is sent to a hydrocracker, which produces hydrocracked naphtha and diesel. Also for the Tampa cases, acid gas generated from the AGR Unit is sent to a sulfuric acid $\left(\mathrm{H}_{2} \mathrm{SO}_{4}\right)$ facility to produce $\mathrm{H}_{2} \mathrm{SO}_{4}$ for the local fertilizer market. Since there is no market for steam at the Tampa site, all steam is routed to a condensing steam turbine for additional power generation. Table RD-2 summarizes the feedstock, products, and fuels for each of the four cases.

Table RD-2

Cases Considered

\begin{tabular}{|c|c|c|c|c|}
\hline & PARFW & PARHCU & TSC & THCU \\
\hline Feed & Petroleum Coke & Petroleum Coke & $\begin{array}{l}\text { Petroleum } \\
\text { Coke }\end{array}$ & $\begin{array}{l}\text { Petroleum } \\
\text { Coke }\end{array}$ \\
\hline $\begin{array}{l}\text { Standby Fuel - } \\
\text { GT }\end{array}$ & Natural Gas & Natural Gas & Diesel & Diesel \\
\hline $\begin{array}{l}\text { Auxiliary Fuel - } \\
\text { HRSG }\end{array}$ & Natural Gas & $\begin{array}{l}\text { Natural Gas \& } \\
\text { HCU Offgas }\end{array}$ & Natural Gas & $\begin{array}{c}\text { Natural Gas \& } \\
\text { HCU Offgas }\end{array}$ \\
\hline Products & $\begin{array}{c}\text { Power } \\
\text { Naphtha } \\
\text { Diesel } \\
\text { Finished Wax } \\
\text { Sulfur } \\
6307 \text { kPa steam } \\
\text { (900 psig steam) } \\
4238 \mathrm{kPa} \text { steam } \\
\text { (600 psig steam) } \\
1136 \mathrm{kPa} \text { steam } \\
\text { (150 psig steam) }\end{array}$ & $\begin{array}{c}\text { Power } \\
\text { Naphtha } \\
\text { Diesel } \\
- \\
\text { Sulfur } \\
6307 \text { kPa steam } \\
\text { (900 psig steam) } \\
4238 \mathrm{kPa} \text { steam } \\
\text { (600 psig steam) } \\
1136 \mathrm{kPa} \text { steam } \\
\text { (150 psig steam) }\end{array}$ & $\begin{array}{c}\text { Power } \\
\text { Syncrude } \\
- \\
\text { - } \\
\text { Sulfuric Acid } \\
\text { - } \\
- \\
-\end{array}$ & $\begin{array}{c}\text { Power } \\
\text { Naphtha } \\
\text { Diesel } \\
\text { - } \\
\text { Sulfuric Acid } \\
\text { - } \\
- \\
\text { - }\end{array}$ \\
\hline
\end{tabular}

Case PARFW: $\quad$ Port Arthur Refinery Finished Wax. The hydrocarbon liquids produced from the F-T reactor are upgraded into three different products - hydrotreated naphtha, diesel, and finished wax.

Case PARHCU: Port Arthur Refinery Hydrocracking Unit. The hydrocarbon liquids produced from the F-T reactor are sent to a hydrocracker, which produces diesel and naphtha.

Case TSC: $\quad$ Tampa Syncrude. The hydrocarbon liquids produced from the F-T reactor are dewaxed to produce synthetic crude.

Case THCU: Tampa Hydrocracking Unit. The hydrocarbon liquids produced from the F-T reactor are sent to a hydrocracker, which produces diesel and naphtha. 
Block flow diagrams for each of these cases can be found in Task 2, Figures 2.2.2-1 through 2.2.2-4.

\section{Economic Modeling of the Process Cases}

Upon completion of process engineering studies for each site, the final selection was based primarily on financial return calculations produced by an economic model. This model was developed using Microsoft Excel software and provided the ability to change various input parameters and note their affect on the financial calculations. The process studies were conducted first, however, in order to provide the necessary inputs to the model such as product quantities, utility requirements, and capital and operating cost estimates. Prior determination of the site selection criteria helped provide objective supporting information for development of the cost estimates, product market values, transportation costs, inflation rates, etc., that were incorporated in the model.

The inputs used in the economic model included:

- Feedstock prices on an annual basis

- Any product price on an annual basis or an inflator basis

- Capital cost (leveraged and unleveraged)

- Natural gas prices on a yearly basis or by varying inflators

- Maintenance costs on an annual basis to allow for required turnaround periods

- Process availability

- Separate on-stream reliability factors for gasification, F-T Synthesis, and power generation

- Inflation factors for operation and maintenance costs

- Independent electrical inflation rates

- Independent labor rate inflation factors

The model provided the following financial calculations:

- Net Present Value (NPV) - Defined as the current dollar value today of the annual future net cash flows discounted by the cost of capital.

- $\quad$ Present Worth Index (PWI) - Defined as the ratio of the present value of cash inflows to the present value of the cash outflows. PWI measures the relative attractiveness of projects per dollar of investment.

- Present Worth Payout (PWP) - Defined as the time it takes to recover an investment in terms of present value dollars. It represents the elapsed time (expressed in years) it takes for the present value of the net cash inflows to equal the present value of the net cash outflows. It is measured from the initial outflow of funds.

- Discounted Cash Flow Return On Investment (DCFROI) - Defined as the discount rate which equates the project's discounted net cash inflows with its discounted net cash outflows. It can also be interpreted as the return on investment that allows the project's net cash inflows to reduce the present value of the investment to zero.

A total of 17 economic analyses of the refinery and power generation station cases were run with various inputs. Table RD-3 summarizes the results of these calculations. 


\section{Economic Analysis Results of the Process Cases}

After the four process cases were developed an economic data were developed for each of the cases. The process data and economic data was inputed into the economic model. Table RD-3 gives a summary of the economic cases and results.

\section{Table RD-3 Summary of EECP Economic Model Results}

\begin{tabular}{|c|c|c|c|c|}
\hline & NPV & PWI & PWP & DCFROI \\
\hline \multicolumn{5}{|l|}{ PARFW Cases: } \\
\hline - Economic Model Base Case & $(49,071,775)$ & -0.77 & $\mathrm{~N} / \mathrm{A}$ & $6.17 \%$ \\
\hline - $\quad$ Electric sales @ \$35/MW & $(28,868,309)$ & 0.86 & $\mathrm{~N} / \mathrm{A}$ & $8.04 \%$ \\
\hline - Investment reduction of $\$ 30 \mathrm{MM}$ & $(28,785,101)$ & -0.84 & $\mathrm{~N} / \mathrm{A}$ & $7.70 \%$ \\
\hline - Operating expense reduction of $\$ 5 \mathrm{MM}$ & $(23,749,572)$ & -0.89 & $\mathrm{~N} / \mathrm{A}$ & $8.48 \%$ \\
\hline $\begin{array}{ll}\text { - } & \text { Investment reduction (\$30 MM), OPEX } \\
& \text { reduction (\$5 MM), and sales @ \$35/MW }\end{array}$ & $16,740,567$ & 1.09 & 13.96 & $12.03 \%$ \\
\hline - Best case with petroleum coke @ - $\$ 10 /$ ton & $32,262,309$ & 1.18 & 12.29 & $13.41 \%$ \\
\hline - $\quad$ Best case with oil @ \$30/barrel & $31,604,405$ & 1.18 & 12.41 & $13.33 \%$ \\
\hline - $\quad$ Best case with oil @ \$20/barrel & $1,876,730$ & 1.01 & 15.97 & $10.67 \%$ \\
\hline PARHCU Economic Model Base Case & $(98,286,943)$ & -0.54 & $\mathrm{~N} / \mathrm{A}$ & $0.82 \%$ \\
\hline TSC Economic Model Base Case & $(158,700,398)$ & -0.35 & $\mathrm{~N} / \mathrm{A}$ & $-5.75 \%$ \\
\hline \multicolumn{5}{|l|}{ THCU Cases: } \\
\hline - Economic Model Base Case & $(150,949,319)$ & -0.39 & $\mathrm{~N} / \mathrm{A}$ & $-4.01 \%$ \\
\hline - $\quad$ Electric sales @ \$35/MW & $(114,017,914)$ & -0.54 & $\mathrm{~N} / \mathrm{A}$ & $0.64 \%$ \\
\hline - $\quad$ Electric sales @ \$40/MW & $(87,677,831)$ & -0.64 & $\mathrm{~N} / \mathrm{A}$ & $3.33 \%$ \\
\hline - $\quad$ Electric sales @ \$45/MW & $(61,337,748)$ & -0.75 & $\mathrm{~N} / \mathrm{A}$ & $5.71 \%$ \\
\hline $\begin{array}{l}\text { - Investment reduction ( } \$ 30 \mathrm{MM}), \text { OPEX } \\
\text { reduction ( } \$ 5 \mathrm{MM}) \text {, Electric sales @ } \\
\$ 40 / \mathrm{MW}\end{array}$ & $(42,068,955)$ & -0.80 & $\mathrm{~N} / \mathrm{A}$ & $6.90 \%$ \\
\hline $\begin{array}{l}\text { - Investment reduction ( } \$ 30 \mathrm{MM}), \text { OPEX } \\
\text { reduction (\$5 MM), Electric sales @ } \\
\$ 45 / \mathrm{MW}\end{array}$ & $(15,728,871)$ & -0.93 & $\mathrm{~N} / \mathrm{A}$ & $9.21 \%$ \\
\hline $\begin{array}{l}\text { - Investment reduction ( } \$ 45 \mathrm{MM}), \text { OPEX } \\
\text { reduction ( } \$ 5 \mathrm{MM}) \text {, Electric sales @ } \\
\$ 40 / \mathrm{MW}\end{array}$ & $(31,925,618)$ & -0.84 & $\mathrm{~N} / \mathrm{A}$ & $7.64 \%$ \\
\hline
\end{tabular}

Overall, the factors having the greatest impact on the selection were:

- The location differentials for petroleum coke was substantial with the petroleum coke having a $\$ 0 /$ ton cost at the refinery location but an $\$ 18 /$ ton cost at the power plant due to transportation and handling costs. Revenues from the sale of electric power were surveyed at the two locations and were higher at the power generation site, but the additional revenue was not sufficient to offset the petroleum coke transportation 
cost. In fact, this difference resulted in a substantial economic disadvantage to the EECP concept being located at the power generation site.

- Electric power, steam, and F-T products can be more effectively integrated into a refinery operation than a power generation operation due to greater infrastructure compatibility for the refinery application.

- The typical refinery application has a greater degree of similar type unit operations and the core competencies to incorporate the processes and operations associated with the EECP concept.

- Economies of scale required for a power generation site are larger than the EECP concept design basis. The power generation station application would require a facility at least twice as large as refinery EECP size to have similar economic performance.

- There is an increased thermal efficiency for the EECP concept in a refinery location since the heat from the F-T process can be used directly without any reduction in mechanical efficiency due to conversion to another form of energy.

- Sulfuric acid manufacture required at the power generation site was not economical for the EECP concept design size.

As can be seen, the Port Arthur Refinery "Finished Wax" (PARFW) base case resulted in the best financial performance when compared to the other three base cases for PARHCU, TSC, and THCU. As a result, the PARFW case was considered to have the greatest economic opportunity for deployment of the EECP concept. Subsequently, inputs were varied for this case in order to examine the financial results under different conditions such as; higher rates for electricity sales, reduced capital cost, reduced operating cost, a combination of these assumptions, and various oil prices. The table also shows additional variations run for the THCU case.

Based on these results, the PARFW case at the Port Arthur Refinery was selected for further development for the EECP concept.

\section{Description of Process Studies Performed}

In order to develop the EECP concept, it was also necessary to conduct several process studies. Some of these studies were generic, or non-site specific, while others were site-specific. The generic studies included:

- F-T Reactor Feed Gas Optimum Hydrogen $\left(\mathrm{H}_{2}\right)$ to Carbon monoxide (CO) Ratio

- F-T Product Upgrade Options

- F-T Wastewater Treating/Utilization

- F-T Catalyst/Wax Separation (performed outside the scope of this program)

- F-T Reactor Feed Gas Percent Carbon Dioxide $\left(\mathrm{CO}_{2}\right)$

- F-T Tail Gas Utilization

Site-specific studies included:

- Process and Heat Integration

- Acid Gas Removal 


\section{The Generic Studies:}

\section{F-T Reactor Feed Gas Optimum Hydrogen $\left(\mathrm{H}_{2}\right)$ to Carbon monoxide (CO) Ratio}

The main objective of this study was to determine the optimum F-T feed gas $\mathrm{H}_{2}$ to $\mathrm{CO}$ ratio for the EECP. The F-T Synthesis Unit converts syngas into hydrocarbon liquids using either a cobalt-based catalyst or iron-based catalyst. For the cobalt-based catalyst, the general consensus is that $\mathrm{H}_{2}$ :CO ratio of 2 in the syngas feed to F-T is desirable. For the iron-based catalyst, due to water gas shift reaction, there is less certainty of the optimum $\mathrm{H}_{2}$ : $\mathrm{CO}$ ratio. When petroleum coke is fed into the gasifier, the syngas produced from the gasifier has a $\mathrm{H}_{2}: \mathrm{CO}$ ratio of only 0.6 to 0.8 . One option is to send the syngas into the F-T Unit without making any adjustment to the $\mathrm{H}_{2}$ : $\mathrm{CO}$ ratio. This option is called the low $\mathrm{H}_{2}$ :CO ratio feed gas. The other option is to raise the $\mathrm{H}_{2}: \mathrm{CO}$ ratio in the syngas closer to 2, similar to cobalt-based F-T Synthesis and then send it to the F-T Synthesis Unit. This option is called high $\mathrm{H}_{2}: \mathrm{CO}$ ratio feed gas. There are a number of ways to raise the $\mathrm{H}_{2}$ : $\mathrm{CO}$ ratio. The following is a brief description of all the cases studied:

- Case A - Low $\mathrm{H}_{2}: \mathrm{CO}$ ratio: $\mathrm{No}_{2}$ : $\mathrm{CO}$ adjustment is made to the syngas produced from gasifying petroleum coke. The syngas feed to the $\mathrm{F}-\mathrm{T}$ reactor has a $\mathrm{H}_{2}: \mathrm{CO}$ ratio of 0.76 .

- $\quad$ Case B - High $\mathrm{H}_{2}$ :CO ratio: Syngas produced from the gasifier is sent to a shift reactor, which shifts a portion of $\mathrm{CO}$ present in the syngas into $\mathrm{H}_{2}$, thus raising the $\mathrm{H}_{2}: \mathrm{CO}$ ratio to 1.9 .

- $\quad$ Case $\mathrm{C}$ - High $\mathrm{H}_{2}$ :CO ratio: Syngas produced from the gasifier is mixed with $\mathrm{H}_{2}$-rich syngas produced from a natural gas Steam Methane Reforming Unit (SMR). The combined syngas has a $\mathrm{H}_{2}: \mathrm{CO}$ ratio of 1.9 .

- Case D - High $\mathrm{H}_{2}$ :CO ratio: Syngas produced from the gasifier is mixed with pipeline $\mathrm{H}_{2}$ to reach a $\mathrm{H}_{2}: \mathrm{CO}$ ratio of 1.9 .

To minimize the total number of cases studied, the size of the F-T synthesis reactor, the volumetric flow rate of syngas feed to the F-T reactor, and the gas turbine size were kept the same. The different $\mathrm{H}_{2}: \mathrm{CO}$ ratio in the syngas feed results in different levels of $\mathrm{F}-\mathrm{T}$ liquid production. The unreacted tail gas was mixed with supplemental syngas from the gasifier. The amount of supplemental syngas was varied for each case to fully load the single GE 6FA turbine. For simplification, only one F-T product upgrading option, hydrocracking, was considered. The F-T liquid produced was sent to a hydrocracker to produce naphtha and diesel. Steam was exported. The power produced from the gas turbine more than meets the internal consumption of the plant and excess power was exported. A $-50 \% /+100 \%$ capital cost estimate and operating cost estimates were developed for each case. Economic calculations were then made to determine which case had the highest discounted cash flow return on investment (DCFROI) and net present value (NPV).

For this study, the conclusion was that the lower hydrogen to carbon monoxide ratio (0.76 as compared to 1.9) syngas was more economical for an EECP when the F-T Synthesis is based on use of iron-based catalyst. The economic analysis shows that Case $A$, the low $\mathrm{H}_{2}$ : $\mathrm{CO}$ ratio case, has highest return on investment and greatest net present value. The expenditures required to increase the hydrogen content of the feed 
gas did not improve product yields or quantities sufficiently to improve overall plant economics. Thus, the low $\mathrm{H}_{2}$ : $\mathrm{CO}$ ratio syngas feed, as produced in the gasification section, without any $\mathrm{H}_{2}$ :CO ratio adjustment was used for the completion of remaining tasks of the Phase I feasibility study. Please refer to Task 2, Attachment $\mathrm{C}$ for a summary of the entire study.

\section{F-T Product Upgrade Options}

The purpose of this study was to develop flow schemes and cost estimates for upgrading a nominal 2,500 bpsd of F-T liquids. The information from this study was used to define the type of upgrading and corresponding products that would be economically attractive at selected sites, and for subsequent commercial implementation and marketing studies.

Various options for F-T products upgrading were reviewed for their suitability as part of the overall EECP concept. From these options, the following six cases were selected for further study:

\section{- Stabilized Syncrude}

- Dewaxed Syncrude

- Hydrocracker (Diesel) product

- Lube Oil Products

- Wax Products

- Alpha Olefins

The overall configurations, the advantages/disadvantages, yields and budget-type capital cost estimates were developed.

The cost of the F-T upgrading plant increases as the complexity of the process increases. The alpha olefin case may be slightly simpler and lower cost than the wax case, but requires more analysis and marketing research. Eventually the site location and the local marketing will determine the preferred type of product upgrading. However, there is an incentive to take advantage of the low-volume, high-value components inherent in the F-T liquids. The high value specialty products are lube oil, wax, and alpha olefins rather than commodity transportation fuels. A niche market for premium "environmental" type diesel is a possible exception that can also be readily implemented.

In general, the F-T liquids can be considered as premium feedstock with exceptional inherent qualities, such as negligible sulfur, nitrogen and aromatic content. Hydroprocessing is directionally the most suitable mode of product upgrading to isomerize (dewax), saturate the olefins and remove oxygenates. With hydrocracking, there is a diesel volume increase of over $10 \%$, due to the wax hydrocracking into lighter components and the addition of $\mathrm{H}_{2}$, and a cetane number of more than 70 . For this type of diesel there may be a niche market with public transportation companies. Also hydroprocessing for lube oils and/or waxes is suitable for the low volume, high value niche market.

For a complete report of this study please refer to Task 2, Attachment A. 


\section{F-T Wastewater Treating/Utilization}

The purpose of this study was to develop and evaluate options for treating or utilizing the wastewater stream generated by the F-T synthesis step. The relatively small quantities of mixed alcohol and/or organic acids have little or no market value as chemicals or chemical feedstock.

Three main options, with some variations on some options, for treating and/or utilizing the F-T wastewater stream were evaluated. These included recycling water to the syngas generation unit, pretreatment to remove alcohol before sending the waste stream to the bio-treatment section, and sending the entire waste stream directly to the biotreatment section.

Cost estimates were not developed for the different options since the recycle option was far superior to other options in eliminating the waste stream by totally recycling it in a manner that involves low capital and operating cost.

Please refer to Task 2, Attachment B, for a complete report of the study.

\section{F-T Catalyst/Wax Separation}

For low temperature F-T reactor operating conditions in a Slurry Bubble Column Reactor (SBCR), the heavier hydrocarbon products (wax) remain in liquid phase, thus increasing the height of the slurry catalyst bed with time. It is, therefore, necessary to remove wax continually to keep the slurry height constant without removing catalyst from the reactor. There is not currently a proven commercial method for removing the catalyst from the wax. This is a critical issue that must be resolved. Currently, various separation methods are being evaluated outside of DOE EECP funding. Prior to the detailed design and construction of the EECP project, sufficient work will have been identified for developing an effective means to separate catalyst and wax. Texaco will demonstrate the effectiveness of the separation on a stand-alone system and a small SBCR outside of DOE funding. Texaco will also privately fund construction and testing of a Demonstration Separator for catalyst/wax separation at the DOE Alternate Fuels Development Unit at La Porte, Texas.

Since the methods planned for catalysis wax separation involve existing proprietary designs developed outside of DOE funding, we will identify the successful method and include the design in Phase III.

\section{F-T Reactor Feed Gas Percent Carbon Oxide $\left(\mathrm{CO}_{2}\right)$}

The purpose of this study was to evaluate the impact of the presence of carbon dioxide on the performance of the F-T Synthesis Unit and on the EECP. There are currently no experimental data available to evaluate this impact on the Rentech F-T Synthesis Unit. It was proposed to use an in-house numerical model with literature information to estimate the optimal amount of $\mathrm{CO}_{2}$ in the syngas feed to the F-T Synthesis Unit.

Figures RD-1 and RD-2show the CO conversion on a mole basis and yield of hydrocarbons. 


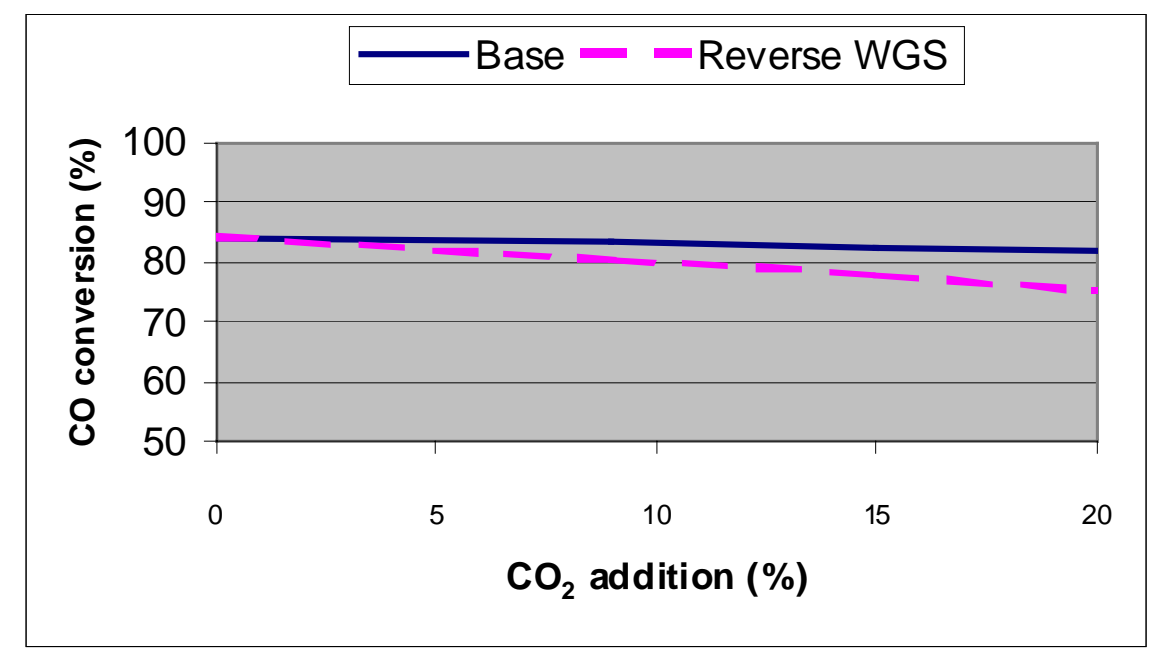

Figure RD-1

$\mathrm{CO}$ Conversion as a Function of $\mathrm{CO}_{2}$ in the Feed

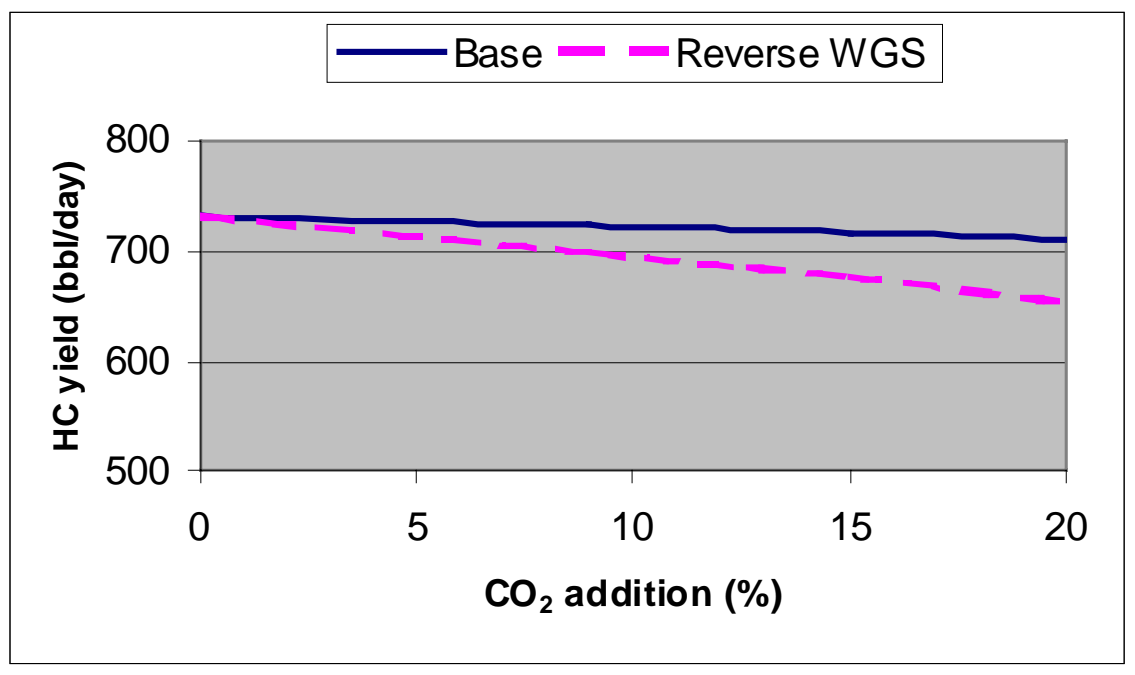

Figure RD-2

Hydrocarbon Yields as a Function of $\mathrm{CO}_{2}$ in the Feed

It is possible that the additional $\mathrm{CO}_{2}$ induces a reverse water gas shift (WGS) reaction. This reaction will produce more water (relative to syngas), lowering the F-T reaction rate (inhibition by water) and yielding even lower conversions and yields than previously expected. These lower values as a function of the percentage of $\mathrm{CO}_{2}$ in the feed are depicted as dashed lines in Figures RD-2 and RD-3. The most likely scenario lies somewhere between the two curves. Nevertheless, optimal reactor performance is obtained with no $\mathrm{CO}_{2}$ in the feed. To validate these results, the effect of $\mathrm{CO}_{2}$ will be determined in laboratory experiments outside the scope of this work, but its effect or lack of effect will be confirmed and reported in Phase II of the EECP project.

This complete study is included in Task 2, Attachment D. 


\section{F-T Tail Gas Utilization Study}

The F-T tail gas is comprised of the unconverted syngas, $\mathrm{CO}_{2}$, and light hydrocarbons that are produced in the F-T reactor. There are many possible options for F-T tail gas usage. The optimum use will depend on the process scheme and the desired products, which can vary with location. Some possible options for tail gas usage include: recycle to syngas generation, recycle to F-T reactor feed, route as feed to a second F-T reactor, use as fuel for power generation, or use as fuel for steam generation and other fuel requirements.

There are important considerations when addressing tail gas utilization, including:

- The carbon efficiency will be increased by recycling the tail gas allowing for increased conversion and F-T liquid production.

- The process efficiency can be increased by recovering the energy content of the tail gas. Since the tail gas is very clean and free of sulfur and other contaminants this option is environmentally preferred.

- Minimizing emissions to the atmosphere.

Since electric power is a product of the proposed EECP facility, F-T tail gas will be sent to the gas turbine for additional power production.

\section{Site Specific Studies:}

\section{Process and Heat Integration Study}

The process integration features incorporated at this stage are:

- Recycle F-T wastewater to the Gasification Unit. (Refer to Section 2.1.2.3, "F-T Wastewater Treatment/Utilization.")

- Use of nitrogen from the ASU for the gas turbine (GT) fuel dilution. Surplus nitrogen from the ASU is introduced into the head-end of the gas turbine combustor and injected into the combustion reaction zone. Additional nitrogen required for power augmentation is added downstream into the post-combustion zone.

- Use of nitrogen from the ASU as stripping gas in the AGR. Medium pressure nitrogen from the ASU is used to strip $\mathrm{CO}_{2}$ from the rich solvent and thereby increase the $\mathrm{H}_{2} \mathrm{~S}$ content of the acid gas to the SRU.

- Use of bleed air from the gas turbine as feed to the ASU. The air extraction system provides for the extraction of air from the gas turbine compressor to supply the ASU with compressed air. Air is taken from the outer casing of the combustor after it passes through the combustor liner and transition piece to achieve the required amount of cooling. This results in some additional air pressure drop relative to compressor discharge pressure and also causes the extracted air temperature to be higher than compressor discharge conditions. The machine air extraction is limited to a maximum allowable value, while still providing adequate combustor delta $\mathrm{P}$ to drive the cooling flows to the turbine nozzle and combustor components. The air extracted in this manner corresponds to approximately one-quarter of all the air needed for the ASU. 
- Utilize oxygen from the ASU in the SRU. Low-pressure oxygen is substituted for air in the SRU to increase the thermal reactor temperature as well as reduce SRU equipment size and cost.

In addition to process stream integration, the following general heat integration steps were taken:

- Approximately $145 \mathrm{MMkJ} / \mathrm{hr}$ (138 MMBtu/hr) of low grade heat from the gasifier was used to preheat the deaerator feed water and LP BFW, and to generate $482 \mathrm{kPa}$ (70 psia)steam.

- Steam header levels in the process portion of the EECP were set to match HRSG, steam turbine, and host site header levels to the maximum possible extent.

- Steam usage within the EECP was rationalized to minimize the number of levels at which the steam was exported or imported.

The approach to integration between the EECP and the host site was tailored for the particular site as follows:

\section{Port Arthur Refinery}

Preliminary work was done on the combined steam balances of the PAR and the EECP to establish the feasibility of exporting all the surplus steam available from the EECP.

The philosophy was to export all available surplus steam from the EECP (process and HRSG) to the refinery steam header system since the EECP does not have a condensing steam turbine. This resulted in the export of:

- $140,000 \mathrm{Kg} / \mathrm{hr}$ of $6307 \mathrm{kPa}$ steam

(308,000 lb/hr of $900 \mathrm{psig})$

- $5,400 \mathrm{Kg} / \mathrm{hr}$ of $4238 \mathrm{kPa}$ steam

- $48,500 \mathrm{Kg} / \mathrm{hr}$ of $1136 \mathrm{kPa}$ steam

$(12,000 \mathrm{lb} / \mathrm{hr}$ of $600 \mathrm{psig})$

$(107,000 \mathrm{lb} / \mathrm{hr}$ of $150 \mathrm{psig})$

A preliminary investigation was made of the steam system at the Port Arthur Refinery (PAR). It consisted of a number of headers fed by a mixture of dedicated fired boilers, waste heat from process units at the refinery, and a number of back-pressure steam turbines, arranged either independently, or in combination with gas turbines. The exhaust from the gas turbine also served as the preheated combustion air stream feeding some of the fired boilers.

It was determined that eliminating a condensing steam turbine from the EECP could decrease capital cost. PAR's extensive steam system can accept steam produced by the EECP. In addition, the refinery can possibly decommission some existing steam generation capacity as a result of importing steam from the EECP. Such decomissioning should reduce the overall operating cost of the refinery.

\section{Acid Gas Removal Study}

The purpose of this study was to define the best technologies to remove $\mathrm{CO}_{2}$, hydrogen sulfide $\left(\mathrm{H}_{2} \mathrm{~S}\right)$ and carbonnyl sulfide (COS) from the gasification syngas before it enters the F-T Synthesis Unit and the General Electric gas turbine. 
Sulfur recovery technologies were selected to match existing technology at each site. A modified Claus SRU with hydrogenation and amine-based tail gas treating was selected for the refinery site and a sulfuric acid plant was selected for the power station site.

Based on past project experience, the following solvent configurations were selected for comparison to be used in the AGR Unit at both sites:

- $\quad$ Case 1 - chemical solvent, methyldiethanolamine (MDEA) at $311 \mathrm{~K}\left(100^{\circ} \mathrm{F}\right)$

- Case 2 - same as above except at $297 \mathrm{~K}\left(75^{\circ} \mathrm{F}\right)$

- Case 3 - physical solvent, Polyethylene Glycol Dimethyl Ether (PGDE) at $311 \mathrm{~K}$ $\left(100^{\circ} \mathrm{F}\right)$

- $\quad$ Case 4 - same as above except at $272 \mathrm{~K}\left(30^{\circ} \mathrm{F}\right)$

Cooling the solvent below $311 \mathrm{~K}\left(100^{\circ} \mathrm{F}\right)$ requires the use of refrigeration. Near identical process configurations of $\mathrm{H}_{2} \mathrm{~S}$ absorption, $\mathrm{H}_{2} \mathrm{~S}$ concentration, and solvent stripping sections were used for both solvents. This configuration was selected based upon the common performance requirements for high $\mathrm{CO}_{2}$ diluent recovery for the gas turbine operations, very low-sulfur feed gas for $\mathrm{F}$-T Synthesis, and high $\mathrm{H}_{2} \mathrm{~S}$ content in the stripper offgas. The MDEA process requires an upstream COS hydrolysis reactor and a $\mathrm{H}_{2} \mathrm{~S}$ scavenger unit to meet the same total sulfur specifications achieved by the process.

Capital costs, initial catalyst and chemical costs, annual utility costs, and annual catalyst and chemical costs were developed for each of the four cases. The capital cost estimates were based on a ratioed, sized equipment list with a projected accuracy of $+/-35 \%$.

For the refinery site, MDEA Case 2 was selected for the following reasons:

- Approximately $2 \%$ lower capital cost

- Potential to further reduce capital costs by an additional $2 \%$ by combining AGR and Tail Gas Treating Unit (TGTU) amine strippers, although the impact of this on overall reliability needs to be assessed

- MDEA is already in use at the refinery site

For the power station site, MDEA Case 1 was selected for the following reasons:

- Approximately $1-2 \%$ lower capital cost

- MDEA is already in use at the power station site

The approximate $\$ 10 \mathrm{MM}$ difference between the sites for overall sulfur removal and recovery is due mostly to the higher cost of the sulfuric acid plant at the power station site.

For site selection, the minimum capital cost MDEA case was suggested as the initial base case.

For details of the complete study, please refer to Task 2, Attachment E. 


\section{Description of Proposed EECP Facility}

The selected case to develop the detail study for the Concept Report was the Port Arthur Refinery Finished Wax (PARFW) case.

A block flow diagram of the PARFW case is shown in Figure RD-3.

The proposed EECP facility will coproduce approximately $55 \mathrm{MW}$ of net electric power for export, approximately $130,000 \mathrm{~kg} / \mathrm{hr}$ of $4272 \mathrm{kPa}(286,588 \mathrm{lb} / \mathrm{hr}$ of $620 \mathrm{psia})$ export steam, approximately $104,000 \mathrm{~kg} / \mathrm{hr}$ of $1171 \mathrm{kPa}(229,209 \mathrm{lb} / \mathrm{hr}$ of $170 \mathrm{psia})$ export steam, approximately $2,025 \mathrm{~kg} / \mathrm{hr}$ (360 bpd) of finished high-melt wax, approximately $509 \mathrm{~kg} / \mathrm{hr}$ (97 bpd) of finished low-melt wax, approximately $125 \mathrm{bpd}$ of F-T diesel, approximately 35 bpd of F-T naphtha, approximately 89 short tons per day of sulfur, and consume approximately 1,235 short tons per day of petroleum coke. Additional quantities of power and steam will be produced and consumed internally.

Petroleum coke from the Port Arthur Refinery (PAR) Delayed Coking Unit (DCU) is ground, mixed with water and pumped as a thick slurry to the Gasification Unit. This coke slurry is mixed with high-pressure oxygen from the Air Separation Unit (ASU) and a small quantity of high-pressure steam in a specially designed feed injector mounted on the gasifier. The resulting reactions take place very rapidly to produce synthesis gas, also known as syngas, which is composed primarily of hydrogen, carbon monoxide, water vapor, and carbon dioxide with small amounts of hydrogen sulfide, methane, argon, nitrogen, and carbonyl sulfide. The raw syngas is scrubbed with water to remove solids, cooled, and then forwarded to the Acid Gas Removal Unit (AGR), where the stream is split. One portion of the stream is treated in the AGR to remove $\mathrm{CO}_{2}$ and $\mathrm{H}_{2} \mathrm{~S}$ and then forwarded to the F-T Synthesis Unit. The other portion is treated in the AGR to remove the bulk of $\mathrm{H}_{2} \mathrm{~S}$ with minimal $\mathrm{CO}_{2}$ removal and then forwarded as fuel to the General Electric frame 6FA gas turbine. In the AGR solvent regeneration step, nitrogen from the ASU is used as a stripping agent to release $\mathrm{CO}_{2}$. The resulting $\mathrm{CO}_{2}$ and nitrogen mixture is also sent to the gas turbine, which results in increased power production and reduced nitrogen oxides emissions. The bulk of the nitrogen is also sent to the gas turbine as a separate stream, where its mass flow also helps increase the power production and reduce nitrogen oxide emissions.

Overall, approximately $75 \%$ of the sweetened syngas is sent to the gas turbine as fuel. The remaining $25 \%$ is first passed through a zinc oxide bed arrangement to remove the remaining traces of sulfur and then forwarded to the Fischer-Tropsch Synthesis Unit. In the F-T reactor, carbon monoxide and hydrogen react, aided by an iron-based catalyst, to form mainly heavy straight-chain hydrocarbons. Since the reactions are highly 


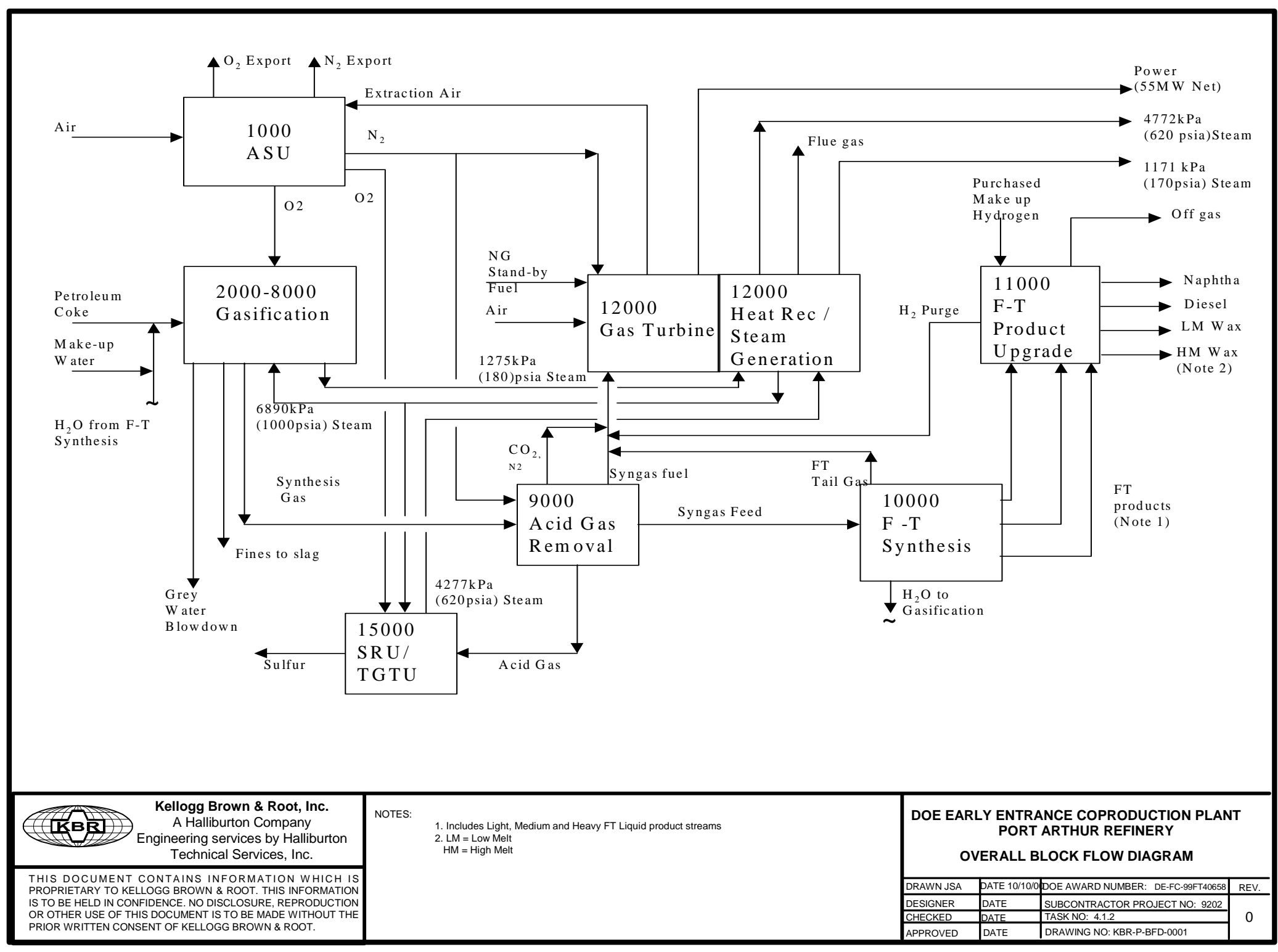

Figure RD-3

Overall Block Flow Diagram 
exothermic, cooling coils are placed inside the reactor to remove the heat released by the reactions. Three hydrocarbon product streams, heavy F-T liquid, medium F-T liquid, and light $\mathrm{F}-\mathrm{T}$ liquid are sent to the $\mathrm{F}-\mathrm{T}$ product upgrading unit while $\mathrm{F}-\mathrm{T}$ water, a reaction byproduct, is returned to the Gasification Unit and injected into the gasifier. The F-T tail gas and AGR offgas are sent to the gas turbine as fuel to increase electrical power production power production by $11 \%$.

In the F-T Product Upgrading Unit (F-TPU), the three F-T liquids are combined and processed as a single feed. The unit consists of a Hy-Finishing ${ }^{\mathrm{TM}}$ reactor, product separators, an atmospheric fractionator, naphtha stabilizer, a vacuum distillation tower, feed preheaters, hydrogen compression facilities, and product coolers. The reaction is carried out at elevated pressure and temperature. A mixture of feed hydrocarbons and hydrogen-rich gas is fed to the top of the fixed bed reactor. In the presence of a hydrotreating catalyst, hydrogen reacts slightly exothermally with the feed to produce saturated hydrocarbons, water, and some hydrocracked light ends. The resulting four liquid product streams are naphtha, diesel, low melt wax, and high melt wax. Each of these streams is sent to segregated product storage tanks. The wax tanks are insulated and equipped with steam coils to maintain the storage temperature above the wax melting point. All of the products leave the EECP facility via tank truck. Transfer pumps and truck loading facilities are provided adjacent to the storage tanks.

The power block consists of a GE PG6101 (FA) $60 \mathrm{~Hz}$ heavy-duty gas turbine generator and is integrated with a two-pressure level heat recovery steam generator (HRSG) and a non-condensing steam turbine generator. The system is designed to supply a portion of the compressed air feed to the ASU, process steam to the refinery, and electrical power for export and use within the EECP facility. The gas turbine has a dual fuel supply system with natural gas as start-up and backup fuel, and primary fuel as a mixture of syngas from the gasifier, offgas from the AGR Unit, and tail gas from the F-T Synthesis Unit. Nitrogen gas for injection is supplied by the ASU for NOx abatement, power augmentation, and the fuel purge system. The combustion system design, including appropriate fuel nozzles, will require new design testing and validation. The heat recovery steam generator is a two-pressure, non-reheat, natural circulation type with horizontal gas flow and vertical fin tubes in all sections. It is arranged with a highpressure (HP) superheater, HP drum and evaporator, HP economizer, intermediate pressure (IP) superheater, IP drum and evaporator, and IP economizer. High pressure steam is produced at 1,000 psia and intermediate pressure steam at 180 psia.

The Praxair ASU is designed as a single train elevated pressure unit. Its primary duty is to provide oxygen to the gasifier and Sulfur Recovery Unit (SRU), and all of the EECP's requirements for nitrogen and instrument and compressed air. However, it can also export surplus oxygen and nitrogen, when available, to the PAR. As mentioned above, ASU nitrogen product applications within the EECP include its use as a stripping agent in the AGR Unit, as a diluent in the gas turbine where its mass flow helps increase power production and reduce NOx emissions, and as an inert gas for purging and inerting. The gas turbine, in return for diluent nitrogen, supplies approximately $25 \%$ of the air feed to the ASU, which helps reduce the size of the ASU's air compressor, hence oxygen supply cost.

Acid gases from the AGR, as well as sour water stripper (SWS) offgas from the Gasification Unit, are first routed to knockout drums as they enter the Claus SRU. After entrained liquid is removed in these drums, the acid gas is preheated and fed along with 
the SWS gas, oxygen, and air to a burner. In the thermal reactor, the $\mathrm{H}_{2} \mathrm{~S}$, a portion of which has been combusted to sulfur dioxide $\left(\mathrm{SO}_{2}\right)$, starts to recombine with the $\mathrm{SO}_{2}$ to form elemental sulfur. The reaction mixture then passes through a boiler to remove heat while generating steam. The sulfur-laden gas is sent to the first pass of the primary sulfur condenser in which all sulfur is condensed. The gas is next preheated before entering the first catalytic bed in which more $\mathrm{H}_{2} \mathrm{~S}$ and $\mathrm{SO}_{2}$ are converted to sulfur. The sulfur is removed in the second pass of the primary sulfur condenser, and the gas goes through a reheat, catalytic reaction, and condensing stage two more times before leaving the SRU as a tail gas. The molten sulfur from all four condensing stages is sent to the sulfur pit, from which product is transported off site by tank truck.

The tail gas from the SRU is preheated and reacted with hydrogen in a catalytic reactor to convert unreacted $\mathrm{SO}_{2}$ back to $\mathrm{H}_{2} \mathrm{~S}$. The reactor effluent is cooled while generating steam before entering a quench tower for further cooling. A slip stream of the quench tower bottoms is filtered and sent along with the condensate from the SRU knockout drums to the SWS. $\mathrm{H}_{2} \mathrm{~S}$ is removed from the quenched tail gas in an absorber by lean methyldiethanolamine (MDEA) solvent from the AGR Unit, and the tail gas from the absorber is thermally oxidized and vented to the atmosphere. The rich MDEA solvent returns to the AGR Unit to be regenerated in the stripper.

The steam system of the EECP serves two main functions: (1) it serves as a medium for exporting a large amount of surplus heat from the EECP to PAR, and (2) it integrates the heat balances between the individual process blocks within the EECP. The system is designed to recover the maximum amount of heat from the EECP and to export it in the form of $4272 \mathrm{kPa}$ (620 psia) and $1171 \mathrm{kPa}$ (170 psia) superheated steam to the refinery. PAR will provide zeolite treated water, which will be passed through a mixed-bed polishing unit to remove final traces of contaminants and produce high-quality deaerator feed water. This water is first preheated by exchange with waste heat streams available from the air separation unit and gasifier, then pumped to the deaerator. Two lowpressure (LP) boiler feed water (BFW) pumps are used to deliver deaerated water to the Gasification Unit where low-grade heat is used to generate $482 \mathrm{kPa}$ (70 psia) saturated steam, which is used within the EECP facility. Other portions of the LP water are sent to the Gasification Unit and HRSG for production of $1275 \mathrm{kPa}$ (185 psia) of saturated steam. A significant portion of this steam is consumed internally within the EECP facility, however, approximately $103,997 \mathrm{~kg} / \mathrm{hr}(229,209 \mathrm{lbs} / \mathrm{hr})$ are superheated in the HRSG and exported to the refinery. The remaining portion of the LP water is passed through the HP boiler feedwater pumps and sent to the HRSG for production of $6890 \mathrm{kPa}(1,000$ psia) of saturated steam. A small portion of that steam is used in the gasifier and SRU, while the remainder is superheated in a HRSG coil before being let down to $4272 \mathrm{kPa}$ (620 psia) through a steam turbine. The steam turbine is used to drive a generator that recovers $2,827 \mathrm{~kW}(3,790$ horsepower) from the letdown steam. Two IP BFW pumps are used to feed deaerated water to both the $2963 \mathrm{kPa}$ (430 psia) and 4,272 kPa (620 psia) headers after heat exchange with a stream from the gasifier. A portion of the water also picks up heat from the F-T Synthesis Unit to produce $2963 \mathrm{kPa}$ (430 psia) saturated steam for use within the EECP. The remainder is let down to the $1226 \mathrm{kPa}$ (185 psia) header. The remainder of the IP BFW is used to generate $4272 \mathrm{kPa}(620 \mathrm{psia})$ saturated steam, which combines with the letdown from the steam turbine and is exported to the PAR. Provisions are included for letting down steam from one header to the next to facilitate control during start-ups or upset conditions. 
A cooling water system is included in the EECP facility. The system consists of a freshwater cooling tower and basin. Motor driven cooling water pumps serve to circulate cooling water between the cooling tower and various cooling water exchangers within the EECP. A vendor-maintained cooling water treatment unit is also provided. Make-up water to the cooling tower is taken from the PAR and cooling tower blowdown is sent to the PAR for treatment.

A flare and associated piping and knockout drum are also provided to handle the full flow of the gasifier in the event that a unit downstream of it should trip.

Firewater and service water systems are provided and connect to the much larger PAR facilities. Services such as sewer, potable water, and oily water systems are also connected to the PAR facilities. In addition, costs for a control room, offices, laboratory, and maintenance shops are included in the EECP capital cost estimate.

The EECP is capable of operation without the F-T Synthesis Unit and the F-TPU. In that case, all of the syngas will be used as fuel to the gas turbine. The gasifier and ASU would then be operating at slightly reduced capacity; however, power and steam export to the refinery would be maintained.

\section{EECP Energy Audit}

An energy assessment study using pinch analysis was performed for the EECP facility. The main objective of this study was to carry out an energy audit of the process and identify opportunities to improve energy recovery of the proposed design. The analysis indicated the proposed process configuration exhibited a high degree of recoverable energy efficiency of about $92 \%$. This efficiency value is considered high at this point in design. The detailed results of the study can be found in Task 4, Attachment A.

\section{EECP Thermal Efficiency}

On a gross heating value basis, the proposed EECP thermal efficiency has been estimated at $66.5 \%$. This calculation is based on processing 1,235 short tons per day of petroleum coke to produce saleable products: $55 \mathrm{MW}$ of net electrical power; 130,000 $\mathrm{kg} / \mathrm{hr}$ of $4272 \mathrm{kPa}(286,588 \mathrm{lb} / \mathrm{hr}$ of $620 \mathrm{psia})$ steam; $104,000 \mathrm{~kg} / \mathrm{hr}$ of $1171 \mathrm{kPa}$ $(229,209 \mathrm{lb} / \mathrm{hr}$ of $170 \mathrm{psia})$ steam; $2,025 \mathrm{~kg} / \mathrm{hr}$ (360 bpd) of finished high-melt wax; 509 $\mathrm{kg} / \mathrm{hr}$ (97 bpd) of finished low-melt wax; $125 \mathrm{bpd}$ of F-T diesel; $35 \mathrm{bpd}$ of F-T naphtha; and 89 tons per day of sulfur.

\section{Market Assessment}

Product type, production volumes, market demand, location factors, niche opportunities, and transportation considerations required adequate definition to achieve reasonable estimates of product value and long-term markets. A Product Valuation Team was formed to consider and weigh these factors and to develop methodologies for arriving at realistic current and future price premises for each product at each location.

Products considered for manufacture by the EECP include F-T naphtha, F-T diesel, finished wax, syncrude, power (and steam), and sulfur. For each of these products, the Product Valuation Team considered valuation methodologies, current market size and growth rate, projected new markets, and niche opportunities. The team established a 
price basis and forecast for future prices to be used in the project's pro forma calculations. The following is a brief summary of the team's assessment for each product.

\section{F-T Diesel}

The current opportunity for F-T diesel is as a blend stock in the distillate market. The U.S. distillate market is a large market of approximately $3.5 \mathrm{MM} \mathrm{bbl/day.} \mathrm{Of} \mathrm{this,} \mathrm{about}$ two-thirds of the volume is used in the transportation area in fuels designed to reduce tailpipe emissions. Distillate demand is forecasted to grow approximately $1 \%$ or 34,000 $\mathrm{bbl} /$ day per year. Of the growth, $88 \%$ will occur in the low-sulfur transportation sector. It is expected that U.S. F-T diesel production will displace low-sulfur diesel blend stock imports.

Pricing for F-T diesel, relative to world crude prices, was established by first adding a small premium to diesel prices to account for the low sulfur and cetane benefits. Product prices were projected over a ten-year period based on world crude oil prices published in December 1999 by the EIA Annual Energy Outlook - 2000. Based on a West Texas Intermediate (WTI) price (at Cushing, OK) of $\$ 29.33$ per barrel, a blend value of the F-T diesel of $\$ 32.23$ per barrel resulted.

In the future, F-T diesel could also be used as a clean fuel alternative in fuel cell automobiles. The absence of sulfur and nitrogen in the fuel eliminates the additional cost and weight of on-board removal components. Chemical applications may also exist for the 9- to 17-carbon normal paraffins. Normal paraffins are primarily used as a building block for linear alkylbenzene sulfonates, a main ingredient in biodegradable detergents. Prices for chemical-grade normal paraffins are typically twice that of high-sulfur diesel. F-T diesel would make a good feedstock for normal paraffin extraction. A narrow cut in the 15- to 17-carbon normal paraffins range would result in a very good synthetic drilling fluid for offshore operations.

\section{F-T Naphtha}

F-T naphtha is composed of $21 \%$ paraffins, $70 \%$ olefins, $9 \%$ oxygenates, and is absent of aromatics, naphthenes, sulfur, and nitrogen. There are generally three different uses for naphthas: 1) direct gasoline blending; 2) reforming to high octane reformate for gasoline blending; and 3) steam cracking to ethylene/propylene.

F-T naphtha is expected to have an initial boiling point (IBP) of approximately $319 \mathrm{~K}$ $\left(115^{\circ} \mathrm{F}\right)$, estimated Reid Vapor Pressure (RVP) of $69 \mathrm{kPa}(10 \mathrm{psi})$, and a research octane number of 53. The high RVP will limit its use as a blending component in summertime gasoline. The low octane number also limits its value as a blending component. F-T naphtha is not considered a suitable reformer feed.

The highest value market for the F-T naphtha will be as a feedstock to the ethylene market and must compete with other feedstocks with current market size estimated at $6 \mathrm{MM}$ tons/year and demand forecasted to grow approximately $5 \%$ per year. Based on a WTI crude price of $\$ 29.33$, the F-T naphtha value for use as a feedstock to the ethylene market is estimated at $\$ 29.35$, which is the price of natural gasoline plus $\$ 0.84$ per barrel premium for its high paraffin content. 
Possible new markets for the light normal paraffins in F-T naphtha include blowing agents for plastics, solvents in the food industry, drying agents in rubber adhesives, paints, and inks.

\section{Finished Wax}

Three finished wax products will potentially be produced from the F-T wax fraction. All are composed of paraffins with a maximum of $0.5 \%$ oil content and of food grade quality. The low melt wax melts at approximately $328 \mathrm{~K}\left(130^{\circ} \mathrm{F}\right)$ and is typically used in candle and paper cup manufacturing. The medium melt wax melts at $333 \mathrm{~K}$ to $339 \mathrm{~K}\left(140^{\circ} \mathrm{F}\right.$ to $150^{\circ} \mathrm{F}$ ) and is used in the candle, adhesive, PVC lubricant, and food manufacturing. High melt wax melts in the range $344 \mathrm{~K}$ to $350 \mathrm{~K}\left(160^{\circ} \mathrm{F}\right.$ to $\left.170^{\circ} \mathrm{F}\right)$ and is used in blending other waxes, adhesives, PVC lubricants, and synthetic rubber. In a refinery, the wax could be used as a high-quality Fluid Catalytic Cracking Unit (FCCU) feed, but at values far below finished wax prices.

The U.S low melt wax market demand is currently $800 \mathrm{MM} \mathrm{lb} /$ year or $7,200 \mathrm{bbl} /$ day. The demand is supplied through domestic production and imports. The U.S. medium melt wax market demand is currently $500 \mathrm{MM} \mathrm{lb/year}$ or $4,500 \mathrm{bbl} /$ day. The demand is also supplied through domestic production and imports.

The candle industry demand is growing at a rate of $3 \%$ per year, led by the high aromatic candle demand. Conversely, the paper cup demand is shrinking $1 \%$ per year due to competition from polystyrene cups. Medium melt wax demand is expected to grow at a rate of $2 \%$ per year, primarily due to the candle and adhesives markets.

Low melt prices are currently $\$ 0.27$ to $\$ 0.29$ per pound or $\$ 82$ to $\$ 88$ per barrel. Medium melt prices are currently $\$ 0.29$ to $\$ 0.31$ per pound or $\$ 88$ to $\$ 97$ per barrel. High melt prices are currently $\$ 0.30$ to $\$ 0.33$ per pound or $\$ 91$ to $\$ 100$ per barrel. Current high melt prices are depressed due to a short-term oversupply.

Prices for low melt wax are expected to remain at these levels despite increasing demand due to pressure from Far East imports. Imports are also expected to keep medium melt prices relatively flat. High melt prices are expected to recover in approximately two years to $\$ 100$ to $\$ 109$. After 2005 , prices are estimated to increase $1 \%$ per year. The lack of imports will help support domestic prices.

\section{Syncrude}

Syncrude, derived as a F-T product, was valued using the methodology of comparing to crudes with similar specifications and adjusting for quality and yield differences. The syncrude was compared to light, low-sulfur, United States Gulf Coast (USGC) crude with 36.6 API gravity. A comparison of the theoretical yields, with product values applied, revealed a discount of $\$ 0.40$ per barrel for the syncrude. Transportation cost of the syncrude to other USGC locations, in small quantities, further discounted the product another $\$ 3.00$ per barrel.

\section{Sulfur}

In the U.S. during 1999, approximately 11 million metric tons of elemental sulfur and byproduct sulfuric acid were produced in 149 locations. The value of the shipments was 
about $\$ 320$ million. World production of all forms of sulfur totals 56 million tons per year. Canada, the second largest sulfur producer in the world behind the U.S. and the world's largest exporter of sulfur, has 11 million metric tons of sulfur stockpiled awaiting more favorable pricing.

Domestic sulfur is produced by the following methods:

- Naturally mined elemental sulfur is known as Frasch sulfur since it is recovered using the Frasch process. Hot water is used to melt the underground element and compressed air is used to transport it to the surface. Only one U.S. company is still producing Frasch sulfur at an offshore mine. Weather conditions and weak market prices have forced many mines to close. Current U.S. Frasch production is less than two million tons per year and is expected to remain relatively unchanged.

- Recovered elemental sulfur is the byproduct of petroleum refineries, natural gas processing plants, and coking operations in over 120 plants. 1999 production was 8 million metric tons.

- Byproduct sulfuric acid is derived from nonferrous metal roasters and smelters. The majority of the roughly one million metric tons/day 1999 production emanates from copper mine smelters.

Worldwide, sulfur supply is very similar to the U.S. market situation. Frasch sulfur production is flat or dropping while recovered and byproduct sulfur supply is increasing due primarily to environmental restrictions that have reduced the overall level of permitted sulfur emissions. Within the U.S., there is a net import and consumption of two million metric tons of elemental sulfur and byproduct sulfuric acid. Eighty percent of the total consumed sulfur is either used as or converted to sulfuric acid and employed as a chemical reagent. Agricultural industries lead in sulfur consumption for phosphoric acid production as an intermediary to phosphatic fertilizers. Petroleum refining is second and copper ore leaching is third in industrial sulfur consumption.

From 1981 to 1998 , there was a 0.3 percent growth in the U.S. market. Due to increasing recovered sulfur supply from increasingly strict environmental regulations and weak projected demand for diammonium phosphate fertilizer, a $-2 \%$ negative growth is projected for the next decade.

From 1981 to 1998 , pricing for elemental sulfur has ranged from a high of $\$ 158$ per long ton to a low of $\$ 70$ per long ton at Tampa, Florida. Current pricing is about $\$ 67.50$ per long ton at Tampa. Tampa pricing is normally the highest possible domestic price due to the high demand for sulfur in the Florida area. U.S. West Coast prices could be as low as less than $\$ 1$ per long ton. The low price there is due primarily to preparation and shipping costs for overseas delivery. The average value of all domestic shipments was $\$ 29.14$ in 1999.

With increased supply primarily from recovered sulfur sold at relatively low prices and slightly decreasing demand due to low growth in the domestic fertilizer industry, a $-1 \%$ downward price trend is predicted for the next decade. 
Sulfur is a major mineral commodity used primarily as a chemical reagent. It has a very well-defined market use in the fertilizer and sulfuric acid industries. Due to its long-term availability, widespread supply and relatively stable current market, no new projected markets of any significant impact are anticipated.

\section{Power}

Establishing a current market size for electric power is difficult because of the level of interconnections in the Port Arthur-Beaumont, Texas, area. An assessment of the power companies in the area and the level of interconnections concluded that the market is unlimited for the relatively small size EECP production, with an export level of only approximately $55 \mathrm{MW}$.

The Port Arthur-Beaumont, Texas area is in the Entergy market arena, interconnecting with The Southern Company, Tennessee Valley Authority (TVA), Southwest Power Pool (SPP), and Southwest Electric Power Company (SWEPCO). In addition, SPP is interconnected to the Mid-Continent Area Power Pool (MAPP). With this level of interconnections, the EECP project should not have any constraints to potential sales as it wheels into any of these market areas.

For this project, power pricing using current dollars was estimated at $\$ 44 / \mathrm{MW}$ and descalated at $2.3 \%$ per year for four years and limited descalation thereafter.

\section{Steam}

Steam pricing is based on the equivalent value of the natural gas required to produce the steam using EIA's delivered natural gas pricing for electrical generation for the low case and a projected $\$ 3.25 / \mathrm{Mbtu}$ in 2006 based on current dollars for the high case.

\section{Environmental Assessment}

A preliminary assessment of environmental issues associated with the proposed siting of the EECP was undertaken as part of the site selection process in Tasks 2 and 6 . The intent of this first assessment was to identify significant differences between the environmental issues at each site so that their impact upon the technical and economic feasibility of an EECP at a site could be properly quantified and factored into the site selection process.

After selection of the Port Arthur Refinery site and more improvement of the integration of the EECP with the host site, the environmental issues were reassessed in Task 7. The work in this task consisted of identifying the relevant environmental requirements that would be imposed on an EECP implementation at Port Arthur, and of quantifying the expected emissions from an EECP. Several opportunities for integration of the environmental control technologies with the host site are identified. This integration results in lower costs without compromising environmental concerns. The overall work accomplished in Task 7 will provide a strong basis for further environmental evaluations as part of Phase III of this project. 


\section{Economic Assessment}

The economics of the EECP were evaluated at two points during Phase I; first during the site selection process (Tasks 2 and 6) and second after the facility configuration was determined for the Port Arthur Refinery site (Task 8). The assessments were performed by using a proprietary economic model that was developed using Microsoft Excel software. It provided the ability to change various input parameters and note their affect on various financial return calculations.

Once the EECP concept was developed for the PARFW case, several runs of the economic model were made for various scenarios. Details of the various runs, including capital and operating cost estimates, along with explanations of their basis, are included in Task 8. The results for the base case show a net present value of $\$ 23.1 \mathrm{MM}$ and an internal rate of return (IRR) of $11.9 \%$. The evaluation from preliminary financing review indicates that an IRR of $15 \%$ to $15.5 \%$ would be required for this project to obtain consideration.

A potential improvement in economics involves the role Government and/or Government incentives could play. DOE's assistance in supporting incentives or tax relief could be beneficial. These incentives could include:

- DOE's support and assistance in proposing Federal legislation to exempt F-T fuels and blends from Section 4081 Federal Motor Fuel Excise Tax, and

- DOE's support for a grant to compensate for local and/or state sales and use tax actually paid by the EECP project or its members for tangible personal property that is a component of the project.

The exemption of F-T motor fuels and motor fuels blends containing F-T fuels from Section 4081 Federal Motor Fuel Excise Tax would give an incentive for the various states authorities to also eliminate state taxes. This combination of tax exemption would result in giving a margin advantage of the $\mathrm{F}-\mathrm{T}$ fuel or fuel containing $\mathrm{F}-\mathrm{T}$ blends of approximately $\$ .23$ per gallon or $\$ 9.66$ per barrel. This would result in a projected increase of IRR on a commercial size EECP project producing 4,000 to 5,000 barrels per day of approximately $1.2 \%$. This increased internal rate of return (IRR) may be the incentive to develop commercial size projects.

A DOE grant to compensate for local and/or state sales and use tax would result in increasing the IRR of the EECP project modeled in this section from $11.9 \%$ on the nominal basis to $12.3 \%$.

Two of Texaco's technology licensors, Rentech and Syntroleum, have applied to the DOE to have F-T Synthesis products certified as "alternative fuels" under the Energy Policy Act (EPACT). The designation of fuel products containing at least $30 \% \mathrm{~F}-\mathrm{T}$ synthesis products as "alternative fuels" under EPACT would help establish these fuels in the marketplace. The DOE's assistance in designating F-T diesel and blends containing F-T diesel as "alternative fuels" would be helpful in making the EECP a commercially feasible project.

This approach will allow the creation of small niche markets for F-T fuels in the order of magnitude of 500 to 2,000 barrels per day as F-T Synthesis plant capacity is increased over time. An example of a niche market would be the fuel supply for mass transit bus 
system in a metropolitan area that may be in an EPA non-attainment area. The F-T blend diesel would produce lower emissions and allow the mass transit system to make the conversion to "alternative fuels" at a minimal cost since the same fueling infrastructure could be used and no engine conversion would be required.

\section{Risk Assessment}

A risk assessment of the EECP facility was performed. The purpose of this effort was to test the interdependencies between units and the effect of individual and collective dependencies on the overall availability of the facility. The facility was modeled as a single train plant, with no spare equipment unless specifically indicated in the equipment list. Planned and unplanned failure data were solicited from team members for each of the elements modeled. Where data did not exist, industry sources were consulted to provide the reliability model with a reasonable basis. Overall planned downtime was not calculated on a process block-by-block basis, as any major outage in one block would have a direct affect on the availability of others. Planned downtime was calculated by identifying the longest planned outage for a given 6-month interval and identifying other planned events that could be performed during that outage, so that no additional downtime would be incurred for these shorter events. Those planned maintenance activities that did not fall into one of the 6-month turnaround intervals were counted as additional outages. Reliability prediction software was utilized to define the initial basis and generate reliability block flow diagrams. Data were inputted into this software for initial analysis and review, then loaded into Microsoft Excel for additional calculations, case comparisons, and development of charts and tables. The initial results indicate an overall EECP facility availability of $78 \%$ with an increase to $80.8 \%$ by sparing the MakeUp Hydrogen Compressor and Hydrogen Recycle Compressor in the F-T Product Upgrading Unit. Further improvements in overall availability may be obtained by selective sparing and/or parallel operation of some equipment. Additional work in this area will be conducted in Phase III.

\section{Technical Barriers}

After the process design completed, an evaluation and assessment was performed to identify and assess the technical barriers that require additional research, development, and testing before the process can be commercialized. Several technical barriers have been identified within the F-T Synthesis Unit, Power Block, F-TPU, and AGR.

The barriers within the F-T Synthesis Unit have been categorized into four main areas: reactor design, catalyst/wax separation, equipment design, and environmental concerns.

Reactor design is critical to ensure that the synthesis reaction will produce the desired yields and offgas and liquid composition for the synthesis gas provided. The main technical barriers within this area are the confirmation of the catalyst performance, hydrodynamics, reactor scale-up, and the design of reactor internals. Catalyst performance has been included under reactor design because it is one of the most important considerations when designing a reactor. An acceptable reactor design will provide good distribution of the syngas within the reactor, manage the chemical energy that is released from the reaction, allow for the products to be removed from the reactor in a controlled fashion, and produce the maximum amount of desired products. The reactor should be the smallest that will maintain the desired reactor yield and selectivity. 
Proper instrumentation must be provided in the reactor to measure slurry concentration, bed expansion, temperature gradients, gas holdup, etc.

Catalyst/wax separation is a critical issue that must be resolved. Currently, various separation methods are being evaluated outside of DOE EECP funding. For example, Texaco will demonstrate the effectiveness of the separation on a stand-alone system and a small slurry bubble column reactor (SBCR). Texaco will also privately fund construction and testing of a Demonstration Separator at the DOE Alternate Fuels Development Unit at LaPorte, Texas. Catalyst/wax separation involves the separation of the liquid products of the reaction from the catalyst. The purpose is to remove clean liquid products from the reactor while keeping the catalyst inventory within the reactor. The separation may occur within the reactor or may occur outside of the reactor. In the current design, the catalyst/wax separation is accomplished in two stages. The first stage removes the liquid products as filtrate while maintaining reactor catalyst inventory. The second stage removes the remaining catalyst solids from the liquid products being sent to the F-TPU. The design of the catalyst/wax separation system must be tested and optimized in phase II activities before the F-T Synthesis Unit can be commercialized.

Aside from the F-T Synthesis reactor and the catalyst/wax separation system, there are other equipment items within the F-T Synthesis Unit with unproven design. These items include the fresh catalyst activation vessel, the spent catalyst dump tank, and the catalyst withdrawal and replacement system.

In addition to the equipment design issues, there are some process design and environmental issues that need resolution. These include the disposal of F-T Synthesis catalyst and the use of F-T water in the gasification section. Testing will be required to confirm that the assumed methods are technically feasible.

The GE multi-shaft combined cycle STAG (steam and gas) 106FA system configuration designed for the EECP uses commercially available equipment except for the gas turbine combustion system. The GE 6FA gas turbine has been successfully tested for operation on syngas produced in Texaco gasifiers from a variety of feedstocks such as coal, petroleum coke, vacuum residue, etc. For the EECP proposed, part of the syngas from the Texaco Gasification Unit, after being treated in the AGR, will be sent to the F-T Synthesis Unit for conversion into liquid products. The tail gas from the F-T Synthesis Unit consists of uncondensed reactor products along with unreacted F-T feed gas. The thermal energy content of the F-T tail gas is lower than the syngas. There is no operating experience with the burning of this tail gas in the commercial combustion turbine. The percentage of F-T tail gas that can be burned along with the mixture of Texaco gasifier syngas and offgas from the AGR is not known. Moreover, the gas turbine combustor required in this design will also have air extraction for the ASU and nitrogen injection near the reaction zone for NOx emission control. The gas turbine combustion system will need to be designed and tested before it can be offered for commercial operation.

With regard to technical barriers for F-TPU, the Bechtel Wax Hy-Finishing ${ }^{\mathrm{TM}}$ technology has not yet been applied specifically to the hydrogenation of F-T liquids, although the concept of processing feeds of this composition is commercially proven. Summarily, the barriers to full confidence in the process technology to produce finished wax include: operating conditions of temperature, pressure, hydrogen to hydrocarbon ratio; deactivation rate of the process catalyst; separation of light hydrocarbon byproducts 
produced during the process; and separation of the finished wax into narrow boiling and viscosity ranges without thermal degradation.

The primary technical risk with the AGR is the uncertainty of commercial tray efficiencies at medium pressure in stripping a rich amine with nitrogen at medium pressures. Error in this regard has a potential double negative impact that could result in less $\mathrm{CO}_{2}$ to the gas turbine and more $\mathrm{CO}_{2}$ to the SRU. Other potential risks include: trace or acidic contaminants in the syngas may cause amine degradation and/or corrosion problems, and trace oxygen in the stripping nitrogen may cause formation of heat stable salts and other degradation problems. These risks are judged relatively minimal since they could be addressed by design issues and/or available technologies that would mitigate or eliminate them.

In Phase I, solutions have been assumed for all of the above technical barriers. During Phase II, research, development, and testing will be performed to confirm and to develop solutions to the technical barriers that have been identified. Some of the work will be done within the scope of Phase II of the EECP and some will be performed outside the scope of the EECP. 


\section{CONCLUSION}

We believe the work to date looks promising. The goals to develop and commercialize coproduction technology that produces high value products, particularly those that are critical to our domestic fuel and power requirements, are progressing. And, resolution of critical knowledge and technology gaps on the integration of gasification and downstream processing are also moving forward. Further, there is high interest in the refining industry for this work because of its many synergistic benefits, such as use of a low-value feedstock, production of a variety of clean products, potential for lower overall plant emissions, and improved plant efficiency. In return, the EECP concept requires a facility such as a refinery to act as a heat sink to utilize heat (steam) produced in the process and to share infrastructure expenses. At this point in time, capital cost estimates for the facility are relatively high and work needs to focus on ways to reduce this hurdle. The economics for this small-scale facility are currently fairly marginal and thus, there may be a role for Government incentives to help foster further development of the concept to commercialization.

Site selection efforts culminated in the selection of the Port Arthur Refinery over the Tampa Electric Polk Station as the host site and the Finished Wax case as the optimum configuration. This selection was based on the most favorable economics over three other possible base cases and thirteen variations of those cases. The economics favored the Port Arthur Finished Wax case over the others primarily due to lower feedstock transportation costs, higher product value, and greater infrastructure compatibility. The conceptual design developed for this case during Phase I resulted in an overall cycle efficiency of approximately $66.5 \%$ and an early risk assessment predicts facility availability of $\mathbf{8 0 . 8 \%}$. Opportunities exist to increase both efficiency and availability further during Phases II and III.

A summary of the specific conclusions reached as a result of the process studies undertaken in Phase I follows:

- $\quad$ F-T Reactor Feed Gas Optimum $\mathrm{H}_{2}$ to CO Ratio - Concluded that the additional expenditures required to increase the hydrogen content of the feed gas to the F-T reactor did not improve product yields or quantities sufficiently to improve overall plant economics.

- $\quad$ F-T Product Upgrading - F-T liquids can be considered premium feedstock with exceptional inherent qualities, such as negligible sulfur, nitrogen, and aromatics. After hydrocracking there is an increase in diesel production and a cetane number of more than 70. Niche market opportunities for this type of diesel may exist. Hydroprocessing for wax production is suitable for this low volume, high value niche market product and helps the economics of this small-scale EECP facility.

- $\quad$ F-T Wastewater Treating/Utilization - It is believed that the F-T wastewater generated as a byproduct in the F-T reactor can be recycled to the Gasification Unit at low cost and negligible impact on the process or metallurgy. This will be confirmed in Phase II.

- F-T Catalyst/Wax Separation - There is not currently a proven commercial method for removing the catalyst from the wax. This is a critical issue that must be resolved. Currently, various separation methods are being evaluated outside DOE EECP funding. Prior to the detailed design and construction of the EECP Project, sufficient 
work will have been identified for an effective means to separate catalyst and wax. Texaco will demonstrate the effectiveness of the separation on a stand-alone system, and a small SBCR outside of DOE funding. Texaco will also privately fund construction and testing of a Demonstration Separator for catalyst/wax separation at the DOE Alternate Fuels Development Unit at La Porte, Texas.

- F-T Reactor Feed Gas Percent $\mathrm{CO}_{2}$ - It is expected that optimal F-T reactor performance is obtained with no $\mathrm{CO}_{2}$ in the feed gas. Validation of this will be performed by laboratory experiments, and its effect or lack of effect will be confirmed in Phase II work.

- $\quad$ Process and Heat Integration Study - An energy assessment of the current plant configuration was made using pinch analysis. The analysis showed the design has a high degree of recoverable energy efficiency of about $92 \%$. Opportunities exist to improve this further during Phase III work. Current process integration features include; recycle of F-T wastewater to the Gasification Unit, use of nitrogen from the Air Separation Unit (ASU) for gas turbine fuel dilution, use of nitrogen from the ASU as stripping gas in the Acid Gas Removal Unit (AGR), use of bleed air from the gas turbine combined cycle as feed to the ASU, and use of oxygen from the ASU in the Sulfur Recovery Unit (SRU). In addition to process stream integration, the following general heat integration steps were taken: low-grade heat from the gasifier was used to preheat boiler feed water for the heat recovery steam generator (HRSG); steam header levels in the process portion of the EECP were set to match HRSG, steam turbine, and host site header levels to the maximum possible extent; steam usage within the EECP was rationalized to minimize the number of levels at which the steam was exported or imported.

- $\quad$ F-T Tail Gas Utilization - Since electric power is a product of the EECP facility, F-T tail gas will be sent to the gas turbine and used for additional power production. In other situations the F-T tail gas could potentially be recycled to the gasifier, recycled to the F-T feed gas, or used as fuel in burners, depending on the process scheme and desired products, which can vary with the location.

The technical barriers discussed in Task 4.8 of this report and in the Research, Development, \& Testing Plan, submitted under separate cover, have identified the key areas that need further investigation and development. The barriers associated with the F-T Synthesis Unit have been categorized into four main areas: reactor design, catalyst/wax separation, equipment design, and environmental concerns. Further, the fuel for the gas turbine is a combination of syngas, F-T tail gas, and AGR offgas, which has a lower thermal energy content than syngas alone. Thus, the gas turbine combustion system will need to be designed and tested before it can be offered for commercial operation. In addition, barriers to full confidence in the process technology to produce finished wax include: operating conditions of temperature, pressure, hydrogen to hydrocarbon ratio; deactivation rate of the process catalyst; separation of light hydrocarbon byproducts produced during the process; and separation of the finished wax into narrow boiling and viscosity range without thermal degradation. Solutions to these barriers will be addressed by the work covered under Phase II of the cooperative agreement.

The approach for the EECP was to develop a concept design that would have the greatest opportunity of approaching commercial criteria to ensure that the EECP would actually be built. The consortium of Texaco, Kellogg Brown Root, General Electric, Praxair, and Rentech agreed to design the EECP around a GE PG6101 (FA) gas turbine and a F-T reactor of 8 - to 10 -foot diameter that would resolve any reactor scale-up 
issues for commercial applications. This design was based on a moderate-size electrical generation power unit for which there was reasonable data available to predict that the gas turbine combustor could handle the lower heating value fuel gas resulting from the integration of a power generation plant and a F-T synthesis process. The EECP concept study has confirmed that this approach is a reasonable path to reach the objective of a full-scale facility to demonstrate the EECP concept. For this size facility, we have shifted the F-T product mix to more valuable products to increase the revenue; however, the projected internal rate of return (IRR) of $11.9 \%$ will not meet any of the planned participants' economic criteria hurdles. A review of the Preliminary Project Financing Plan indicates that an IRR of at least 15.0 to $15.5 \%$ will be required to obtain interest from the financial community. From a lender's perspective, this IRR will allow the project to be leveraged in the $60 \%-40 \%$ or $55 \%-45 \%$ debt/equity range given the risk characteristics of the project.

The EECP as presently designed will require an additional non-equity contribution equivalent to $\$ 70 \mathrm{MM}$ of capital to reach the economic hurdle of $15.5 \%$ IRR. The project participants are interested in pursuing opportunities with the DOE to obtain financial support for the construction of the project. We recommend that discussions begin midway through Phase II after several critical milestones of the RD\&T Plan have been reached. 


\section{REFERENCES}

Baker, C. and McGuiness, M.: Mobil Lube Dewaxing Technologies, 1995 NPRA Annual Meeting, San Francisco, Calif., March 19-21, 1995.

Catalyst Activation, U.S. Patent 5,504,118.

Dancuart, L.: Processing of Fischer-Tropsch Syncrude and Benefits of Integrating Its Products with Conventional Fuels, NPRA 2000 Annual Meeting, San Antonio, Texas, March 26-28, 2000.

Foral, A.J. and Al-Ubaidi, B.H.: Evaluation of $\mathrm{H}_{2} \mathrm{~S}$ Scavenger Technologies, GRI Report GRI-94/0197, Aug. 1993.

Gas Processor Suppliers Association: Engineering Data Book, Gas Processors Association, 1987, Revised 10 ${ }^{\text {th }}$ Edition, 1994.

Kohl, A.L. and Risenfeld, F.C.: Gas Purification, $4^{\text {th }}$ Edition, Gulf Publishing Co., Houston, Texas, 1985.

Muller, R.G.: Linear Alpha Olefins, Report No. 12, Stanford Research Institute (SRI), June 1966.

Oukaci, R. and Singleton, A.: High Value Specialty Products from Natural Gas Conversion by Fischer-Tropsch Synthesis, 1999 AIChE Spring National Meeting, March 14-18, 1999.

Shafer, J.R. and Bogadi, J.S.: A Sulfuric Acid Plant in a Refinery Application, Monsanto Enviro-Chem and Conoco, March 3, 1980.

Shah, P.P. et al:: Fischer-Tropsch Wax Characterization and Upgrading - Final Report, UOP Inc., June 1988.

Shah, P.P. and Fullerton, H.E.: Economics of Upgrading Fischer-Tropsch Products, UOP Inc. (for DOE), Nov. 6-8, 1990.

Steib, J.F., Revised Draft of Best Available Control Technology (BACT) Guidance for Gas Turbines (GT), Office of Permitting, Remediation and Registration, Air Permits Division, March 1, 2000.

Stubin, W. et al: : Liquid Products from Petroleum Coke via Gasification and FischerTropsch Synthesis, NPRA 2000 Annual Meeting, San Antonio, Texas, March 26-28, 2000. 


\section{LIST OF ACRONYMS}

\begin{tabular}{|c|c|}
\hline AFDU & Alternate Fuels Development Unit \\
\hline AGR & Acid Gas Removal \\
\hline $\mathrm{AICHe}$ & American Institute of Chemical Engineers \\
\hline AP & Plant Air \\
\hline API & American Petroleum Institute \\
\hline ASU & Air Separation Unit \\
\hline ATM & Atmosphere \\
\hline BACT & Best Available Control Technology \\
\hline $\mathrm{bbl}$ & Barrel \\
\hline BD & Blowdown \\
\hline BFD & Block Flow Diagram \\
\hline BFW & Boiler Feed Water \\
\hline bpd & Barrels per Day \\
\hline bpsd & Barrels Per Stream Day \\
\hline BRS & Brown \& Root Services \\
\hline BTM(s) & Bottom(s) \\
\hline Btu & British Thermal Unit \\
\hline BWF & Black Water Flash \\
\hline CARB & California Air Resource Board \\
\hline CBM & Coal Bed Methane \\
\hline CCP & Commercial Coproduction Plant \\
\hline CEQ & Council on Environmental Quality \\
\hline CFCMS & Carbon Fiber Composite Molecular Sieve \\
\hline CFD & Cubic Feet Per Day \\
\hline $\mathrm{CFI}$ & Cold Flow Improvement Process \\
\hline CFR & Code of Federal Regulation \\
\hline $\mathrm{CO}_{2}$ & Carbon Dioxide \\
\hline COND & Condensate \\
\hline CST & Condensing Steam Turbine \\
\hline CT & Combustion Turbine \\
\hline CW & Cooling Water \\
\hline CWR & Cooling Water Return \\
\hline CWS & Cooling Water Supply \\
\hline DCFROI & Discounted Cash Flow Return on Investment \\
\hline DEIS & Draft Environmental Impact Statement \\
\hline DMPG & Dimethyl Ethers of Polyethylene Glycol \\
\hline $\mathrm{DOE}$ & United States Department of Energy \\
\hline EA & Environmental Assessment \\
\hline EC & Economizer \\
\hline EECP & Early Entrance Coproduction Plant \\
\hline EIS & Environmental Impact Statement \\
\hline EOR & Enhanced Oil Recovery \\
\hline EOR & End of Run \\
\hline EPA & Environmental Protection Agency \\
\hline EPACT & Energy Policy Act \\
\hline EPC & Engineering, Procurement and Construction \\
\hline EPCM & Engineering, Procurement, Construction Management \\
\hline ESD & Emergency Shutdown \\
\hline
\end{tabular}




\begin{tabular}{|c|c|}
\hline EV & Expected Value \\
\hline $\mathrm{EXCH}$ & Exchanger \\
\hline $\mathrm{F}$ & Degree in Fahrenheit \\
\hline FCCU & Fluid Catalytic Cracking Unit \\
\hline FDA & Food and Drug Administration \\
\hline FDEP & Florida Department of Environmental Protection \\
\hline FETC & Federal Energy Technology Center \\
\hline FFBR & Fixed-Fluidized-Bed Reactor \\
\hline $\mathrm{FG}$ & Fuel Gas \\
\hline FONSI & Finding of No Significant Impact \\
\hline FPCS & Functional Process Control Specifications \\
\hline F-T & Fischer-Tropsch \\
\hline F-TPU & Fischer-Tropsch Product Upgrade Unit \\
\hline F-TR & Fischer-Tropsch Reactor \\
\hline GE & General Electric Power Systems \\
\hline GNHP & High Pressure Nitrogen \\
\hline GNP & Gross National Product \\
\hline GT & Gas Turbine \\
\hline GTDL & Gas Turbine Development Laboratory \\
\hline $\mathrm{H}_{2}$ & Hydrogen \\
\hline $\mathrm{H}_{2} \mathrm{O}$ & Water \\
\hline $\mathrm{H}_{2} \mathrm{~S}$ & Hydrogen Sulfide \\
\hline $\mathrm{H}_{2} \mathrm{SO}_{4}$ & Sulfuric Acid \\
\hline HAP & Hazardous Air Pollutant \\
\hline $\mathrm{HC}$ & Hydrocarbon \\
\hline $\mathrm{HCU}$ & Hydrocracking Unit \\
\hline HGU & Hydrogen Generation Unit \\
\hline HHV & Higher Heating Value \\
\hline HMX & Hybrid Multiphase Technology \\
\hline $\mathrm{HP}$ & High Pressure \\
\hline HRSG & Heat Recovery Steam Generator \\
\hline HTR & Heater \\
\hline HTU & Hydrotreating Unit \\
\hline $\mathrm{Hz}$ & Hertz \\
\hline IBP & Initial Boiling Point \\
\hline ICC & Integrated Combined Cycle \\
\hline IGCC & Integrated Gasification and Combined Cycle \\
\hline IGV & Inlet Guide Vane \\
\hline I/O & Input/Output \\
\hline IP & Intermediate Pressure \\
\hline IPCC & Intergovernmental Panel on Climate Change \\
\hline IRCC & Integrated Reforming Combined Cycle \\
\hline IRR & Internal Rate of Return \\
\hline ISBL & Inside Battery Limits \\
\hline JV & Joint Venture \\
\hline K & Degree in Kelvin \\
\hline KAAP & Kellogg Advanced Ammonia Process \\
\hline KBR & Kellogg Brown \& Root, Inc. \\
\hline KBRTC & Kellogg Brown \& Root Technology Center \\
\hline $\mathrm{KJ} / \mathrm{hr}$ & Kilojoule per hour \\
\hline $\mathrm{KO}$ & Knock Out \\
\hline
\end{tabular}




\begin{tabular}{|c|c|}
\hline $\mathrm{kPa}$ & Kilo Pascal \\
\hline KRES & Kellogg Reforming Exchanger System \\
\hline KW & Kilowatts \\
\hline LAB & Linear Alkyl Benzene \\
\hline LAER & Lowest Achievable Emission Rate \\
\hline LAO & Linear Alpha Olefins \\
\hline LD & Liquidated Damage \\
\hline LHSV & Liquid Hourly Space Velocity \\
\hline LHV & Lower Heating Value \\
\hline LNG & Liquefied Natural Gas \\
\hline LP & Low Pressure \\
\hline LPG & Liquefied Petroleum Gas \\
\hline LS & Low Sulfur \\
\hline LSFO & Low Sulfur Fuel Oil \\
\hline LSVGO & Low Sulfur Vacuum Gas Oil \\
\hline LTGC & Low Temperature Gas Cooling \\
\hline M\&EB & Mass and Energy Balances \\
\hline MACT & Maximum Achievable Control Technology \\
\hline MAPP & Mid-Continent Area Power Pool \\
\hline MAT & Micro Activity Test \\
\hline MDEA & Methyldiethanolamine \\
\hline MEA & Monomethanolamine \\
\hline $\mathrm{mm}$ & Millimeter \\
\hline MM & Million(s) \\
\hline MMBtu/hr & Million British Thermal Unit Per Hour \\
\hline MMCFD & Million(s) Cubic Feet Per Day \\
\hline MMKJ/hr & Million Kilojoules Per Hour \\
\hline MMSCFD & Million(s) Standard Cubic Feet Per Day \\
\hline MOC & Materials of Construction \\
\hline MP & Medium Pressure \\
\hline MSD & Material Selection Diagram \\
\hline MT & Metric Ton \\
\hline MTBE & Methyl Tertiary Butyl Ether \\
\hline MTC & Montebello Technology Center \\
\hline $\mathrm{MT} / \mathrm{D}$ & Metric Tons Per Day \\
\hline MTPD & Metric Tons Per Day \\
\hline MW & Megawatts \\
\hline MWE, MWe & Megawatts Electrical \\
\hline $\mathrm{N}_{2}$ & Nitrogen \\
\hline NAAQS & National Ambient Air Quality Standard \\
\hline NACE & National Association of Corrosion Engineers \\
\hline NDT & Non-destructive Testing \\
\hline NEPA & National Environmental Policy Act \\
\hline NESHAP & National Emission Standards for Hazardous Air Pollutants \\
\hline NG & Natural Gas \\
\hline $\mathrm{NH}_{3}$ & Ammonia \\
\hline $\mathrm{NIOSH}$ & National Institute of Occupational Safety and Health \\
\hline NLPM & Normal Liters Per Minute \\
\hline $\mathrm{Nm}^{3}$ & Normal Cubic Meter \\
\hline NNF & Normally No Flow \\
\hline NOC & Normal Operating Conditions \\
\hline
\end{tabular}




\begin{tabular}{|c|c|}
\hline NPDES & National Pollutant Discharge Elimination System \\
\hline NPRA & National Petroleum Refiners Association \\
\hline NPV & Net Present Value \\
\hline NSPS & New Source Performance Standards \\
\hline $\mathrm{O}_{2}$ & Oxygen \\
\hline O\&M & Operations and Maintenance \\
\hline $\mathrm{OH}$ & Overhead \\
\hline OIS & Operator Interface Subsystem \\
\hline OSBL & Outside Battery Limits \\
\hline OSHA & Occupational Health and Safety Act \\
\hline $\mathrm{Pa}$ & Pascal \\
\hline PA & Pump-around \\
\hline PAO & Polyalphaolefins \\
\hline PAR & Port Arthur Refinery \\
\hline PARFW & Port Arthur Refinery Finished Wax Case \\
\hline PARHCU & Port Arthur Refinery Hydrocracking Case \\
\hline PCF & Pounds Per Cubic Feet \\
\hline PD & Positive Displacement \\
\hline PDD & Project Design Data \\
\hline PFD & Process Flow Diagram \\
\hline PFS & Process Flow Sketch \\
\hline PGDE & Polyethylene Glycol Dimethyl Ether \\
\hline PGE & Power Generation Engineering \\
\hline $\mathrm{PI}$ & Instrument Purge \\
\hline PID & Piping and Instrument Diagram \\
\hline PLC & Programmable Logic Controller \\
\hline PLOT & Plot Plan \\
\hline PM & Project Manager \\
\hline PO/MTBE & Propylene Oxide/Methyl Tertiary Butyl Ether \\
\hline PPMVD & Parts Per Millions Volume Dry \\
\hline PPMVW & Parts Per Millions Volume Wet \\
\hline PPMW & Parts Per Millions Weight \\
\hline PSA & Pressure Swing Adsorption \\
\hline PSD & Prevention of Significant Deterioration \\
\hline psia & Pounds Per Square Inch Absolute \\
\hline psig & Pounds Per Square Inch Gauge \\
\hline PUC & Public Utilities Commission \\
\hline$R \& D$ & Research and Development \\
\hline RA & Relief to Atmosphere \\
\hline RD\&T & Research, Development and Testing \\
\hline RFL & Liquid Refrigerant \\
\hline RFV & Vapor Refrigerant \\
\hline ROR & Rate of Return \\
\hline $\operatorname{ROSE}^{\circledR}$ & Residual Oil Solvent Extraction \\
\hline RVP & Reid Vapor Pressure \\
\hline S50 & 50 psig Steam \\
\hline S75 & 75 psig Steam \\
\hline S150 & 150 psig Steam \\
\hline S425 & 425 psig Steam \\
\hline S900 & 900 psig Steam \\
\hline S1500 & 1500 psig Steam \\
\hline
\end{tabular}




\begin{tabular}{|c|c|}
\hline SAP & Sulfuric Acid Plant \\
\hline SBCR & Slurry Bubble Column Reactor \\
\hline SCFD & Standard Cubic Feet Per Day \\
\hline SCHP & High Pressure Steam Condensate \\
\hline SCLP & Low Pressure Steam Condensate \\
\hline SEM & Scanning Electron Microscopy \\
\hline SEP & Separator \\
\hline $\mathrm{SH}$ & Superheater \\
\hline SH\&E & Safety, Health \& Environmental \\
\hline SH600 & Superheated 600 PSIG Steam \\
\hline SIC & Standard Industrial Code \\
\hline SIP & State Implementation Plan \\
\hline SMR & Steam Methane Reforming \\
\hline SOF & Soluble Organic Level \\
\hline SPBC & Slurry Phase Bubble Column \\
\hline SPP & Southwest Power Pool \\
\hline SRU & Sulfur Recovery Unit \\
\hline ST & Steam Turbine \\
\hline STAG & Steam and Gas \\
\hline STG & Storage \\
\hline STM & Steam \\
\hline STPD & Short Ton Per Day \\
\hline STPR & Stripper \\
\hline SWEPCO & Southwest Electric Power company \\
\hline SWRI & Southwest Research Institute \\
\hline SWS & Sour Water Stripper \\
\hline $\mathrm{T} / \mathrm{D}$ & Tons Per Day \\
\hline TBA & Tertiary Butyl Alcohol \\
\hline TBN & To Be Named \\
\hline TBP & True Boiling Point \\
\hline TDC & Texaco Development Company \\
\hline TECO & Tampa Electric Company \\
\hline TEMA & Tubular Exchanger Manufacturers Association \\
\hline TESI & Texaco Energy Systems Inc. \\
\hline TEWAC & Totally Enclosed Water/Air Cooled \\
\hline TFBR & Tubular Fixed-Bed Reactor \\
\hline TGFT & Texaco Gasification Fischer-Tropsch \\
\hline TGP & Texaco Gasification Process \\
\hline TGPS & Texaco Gasification Power System \\
\hline TGTU & Tail Gas Treating Unit \\
\hline THCU & Tampa Hydrocracking Case \\
\hline TIC & Total Installed Cost \\
\hline TNRCC & Texas Natural Resource Conservation Commission \\
\hline TSC & Tampa Syncrude Case \\
\hline TVA & Tennessee Valley Authority \\
\hline $\mathrm{UHC}$ & Unburned Hydrocarbons \\
\hline ULS & Ultra Low Sulfur \\
\hline UOP & Universal Oil Products Inc. \\
\hline U.S. EPA & U.S. Environmental Protection Agency \\
\hline U.S. FDA & U.S. Food and Drug Administration \\
\hline USGC & United States Gulf Coast \\
\hline
\end{tabular}




$\begin{array}{ll}\text { UV } & \text { Ultraviolet } \\ \text { VI } & \text { Viscosity Index } \\ \text { VGO } & \text { Vacuum Gas Oil } \\ \text { VOC } & \text { Volatile Organic Compound } \\ \text { VPPM } & \text { Volume Parts Per Million } \\ \text { WBIP } & \text { Intermediate Pressure Boiler Feed Water } \\ \text { WBHP } & \text { High Pressure Boiler Feed Water } \\ \text { WBLP } & \text { Low Pressure Boiler Feed Water } \\ \text { WBMP } & \text { Medium Pressure Boiler Feed Water } \\ \text { WBS } & \text { Work Breakdown Structure } \\ \text { WGS } & \text { Water-Gas-Shift } \\ \text { WK } & \text { Clarified Water } \\ \text { WPPM } & \text { Weight Parts Per Million } \\ \text { WTI } & \text { West Texas Intermediate } \\ \text { WWTU } & \text { Wastewater Treating Unit } \\ \text { ZnO } & \text { Zinc Oxide }\end{array}$

